\title{
Arañando la superficie: subestimaciones sistemáticas en la política de restitución y sus fuentes ${ }^{\star}$
}

\author{
Scratching the Surface: Systematic Underestimation of Restitution \\ Policy and its Sources
}

Arranhando a superfície: subestimações sistemáticas na política de restituição e as suas fontes

\author{
FRANCISCO GUTIÉRREZ SANÍN ${ }^{* *}$ \\ MARGARITA MARÍN JARAMILLO ${ }^{* * *}$ \\ Paola Perdomo Vaca ${ }^{+}$ \\ Diana MaChUCA PÉREZ ${ }^{++}$
}

FECHA DE RECEPCIÓN: 27 DE JUNIO DE 2017. FeCHA DE ACEPTACIÓN: 31 DE OCTUBRE DE 2017

DOI: http://dx.doi.org/10.12804/revistas.urosario.edu.co/sociojuridicos/a.5883

Para citar este artículo: Gutiérrez Sanín, F., Marín Jaramillo, M., Perdomo Vaca, P., G Machuca Pérez, D. (2018). Arañando la superficie: subestimaciones sistemáticas en la política de restitución y sus fuentes. Estudios Socio-Jurídicos, 20(1), 133-177. doi: http://dx.doi.org/10.12804/revistas.urosario.edu.co/sociojuridicos/a.5883

* El artículo es producto de un proyecto de donación entre Codhes y el Instituto de Estudios Políticos y Relaciones Internacionales (IEPRI) de la Universidad Nacional de Colombia.

** Licenciado en Antropología de la Universidad de los Andes; magíster en Análisis de Problemas Contemporáneos de la Universidad Externado de Colombia y doctor en Ciencia Política de la Universidad de Varsovia. Actualmente es profesor del Instituto de Estudios Políticos y Relaciones Internacionales (IEPRI) de la Universidad Nacional de Colombia y director del Observatorio de Restitución y Regulación de Derechos de Propiedad Agraria. Correo electrónico: fagutierrezs@unal.edu.co

*** Economista Universidad Icesi; magíster en Estadística de la Universidad Nacional de Colombia; estudiante de Doctorado en Estadística de la Universidad Nacional de Colombia. Profesora de la Universidad Sergio Arboleda. Correo electrónico: mmarinj@unal.edu.co. Orcid: 0000-00032139-4558.

+ Socióloga de la Universidad Nacional de Colombia; estudiante de Maestría en Estudios Políticos del Instituto de Estudios Políticos y Relaciones Internacionales (IEPRI). Investigadora del Observatorio de Restitución y Regulación de Derechos de Propiedad Agraria. Correo electrónico: paperdomov@unal.edu.co. Orcid: 0000-0001-6227-5702.

++ Politóloga de la Universidad Nacional de Colombia; magíster en Estudios Políticos del Instituto de Estudios Políticos y Relaciones Internacionales (IEPRI). Investigadora del Observatorio de Restitución y Regulación de Derechos de Propiedad Agraria. Correo electrónico: dxmachucap@ unal.edu.co. Orcid: 0000-0002-4755-3855. 


\section{RESUMEN}

El artículo tiene como propósito evaluar la política de restitución de cinco municipios de la costa Atlántica, a partir de la estimación local que se realiza del número de casos relacionados con la pérdida de la tierra. Mediante este ejercicio, el texto plantea algunos problemas de la política de restitución, entre los cuales se identifican: la debilidad en los conteos y en las cifras sobre los posibles beneficiarios; las demoras del proceso de restitución al momento de iniciar el trámite, y en las fases judiciales; la falta de información sobre el proceso de restitución; el continuo alineamiento de despojadores con las autoridades locales. Al considerar estas dificultades del proceso de restitución, los autores indican la necesidad de complementar estos esfuerzos de la política agraria, junto a otras reformas relacionadas con el acceso a la tierra.

Palabras clave: despojo de tierras, restitución, política agraria, autoridades locales.

\section{ABSTRACT}

This work aims to evaluate the policy of restitution of five municipalities of the Atlantic coast, from the local estimate of the number of cases related to the loss of land that is performed. Through this exercise, the text raises some problems of the restitution policy, among which are identified: firstly, the weakness in the counts and the figures on the possible beneficiaries; the delays in the process of restitution at the time of initiation of the procedure and in the judicial stages; the lack of information on the restitution process; and finally, the continued alignment of despoilers with local authorities. In considering these difficulties in the restitution process, the authors highlighted the need to complement these agrarian policy efforts, along with other reforms related to access to land.

Key words: Land dispossession, restitution, agrarian policy, local policy-makers.

\section{RESUMO}

O artigo tem como propósito avaliar a política de restituição de cinco municípios da Costa Atlântica a partir da estimação local que se realiza do número de casos relacionados com a perda da terra. Mediante este exercício, o texto apresenta alguns problemas da política de restituição, entre os quais se identificam: a debilidade nas contagens e nas cifras sobre os possíveis beneficiários; as demoras do processo de restituição no momento de iniciar o trâmite, e nas fases judiciais; a falta de informação sobre o processo de restituição; o continuo alinhamento de despojadores com as autoridades locais. Ao considerar estas dificuldades do processo de restituição, os autores indicam a necessidade de complementar estes esforços da política agraria, junto a outras reformas relacionadas com o acesso à terra.

Palavras- chave: despojo de terras, restituição, política agraria, autoridades locais. 
Entender a cabalidad las dimensiones de la desposesión de tierras en Colombia - es decir, de la transferencia de bienes y derechos de propiedad de propietarios, ocupantes y tenedores ${ }^{2}$ a grupos armados o terceros-, y cuantificar el número de víctimas de este crimen, es una tarea fundamental por al menos cuatro razones. Primera, para aclarar en qué consistió el fenómeno del despojo y cómo puede ser conceptualizado. Como se verá más adelante, el concepto mismo, pese a su aparente obviedad, sigue siendo problemático. Segunda, y en relación con lo anterior, para poder formular explicaciones adecuadas. ¿Cuáles, por ejemplo, fueron las dinámicas sociales asociadas a niveles más altos de despojo? ¿Cuáles las condiciones institucionales? ¿Cómo interactuaron unas y otras? La literatura relevante tiene intuiciones interesantes sobre el problema, pero aún hay en este terreno mucha tela por cortar. Y el prerrequisito para poder hacer aserciones más o menos generales alrededor de estas preguntas es tener una aproximación plausible sobre la magnitud del fenómeno. Tercera, para evaluar las atribuciones: ¿cuáles fueron los actores más involucrados en él? Ha habido ya debates públicos sobre atribuciones en relación con el desplazamiento (El Espectador, 18 de agosto de 2010; Restrepo, 2012), pero pocos o ninguno alrededor del despojo. Cuarta, y fundamental, para pensar hacia atrás y hacia adelante las políticas públicas relativas al despojo. Hacia atrás, evaluando la eficiencia, suficiencia y capacidad de respuesta de las políticas desarrolladas para responder a él. Hacia adelante, pensando en los diseños que puedan o no ser necesarios para formular políticas que provean mejores respuestas. Todos estos objetivos son centrales para la implementación de una paz estable y duradera, para el resarcimiento de las víctimas, para el perdón y la memoria y, no menos importante, para el desarrollo de las capacidades regulatorias del Estado en relación con la propiedad rural, cuyo déficit ha sido un problema endémico en el país durante décadas (ver, por ejemplo, LeGrand, 2016).

1 En el marco del desarrollo del proyecto agradecemos los aportes de Judith Zableh y Sebastián Bobadilla, quienes hicieron parte del equipo de trabajo.

2 Ni la Ley 1448 ni la cuantificación que presentamos en este texto incluyen en la evaluación la tierra perdida por los tenedores. Es una tarea importante que está pendiente. 
Tanto la literatura académica como reportajes periodísticos (ver, por ejemplo, Verdad Abierta, 2012, 2013, 2016, 2017) sugieren que la desposesión de tierras estuvo lejos de ser un fenómeno marginal. Sin embargo, detrás de aquella valoración se esconden diferentes conceptualizaciones, así como estimativos numéricos que varían enormemente. Para dar un ejemplo de tal variación: en la tabla 1 se observa que, según sea el cálculo, el número de hectáreas afectadas por el despojo va de un poco más de un millón a 10 millones; algo análogo sucede si la unidad de análisis son familias o personas. Las razones subyacentes a estas diferencias tan marcadas pueden residir en una de tres circunstancias, o posiblemente en una combinación de ellas. En primer lugar, las fuentes de información en las que se basan. Algunos se apoyan en fuentes propias y en redes de observadores que tienen en terreno; otros, en bases de datos generadas por el Estado; aun otros, en encuestas. En segundo lugar, la metodología que utilizan. De los trabajos reportados en la tabla 1, solamente Ibáñez, Moya y Velásquez (2006) son explícitos sobre la metodología que usan; y solamente ellos utilizan fuentes de información que en principio son públicas. Garay et al. (2011) ofrecen una narrativa sobre su método para hacer sus estimativos, pero no pudimos acceder ni a los microdatos ni a la explicación completa de cómo llegaron a sus conclusiones. ${ }^{3} \mathrm{Y}$, en tercer lugar, la conceptualización. Legalmente, hay dos grandes categorías que son relevantes para el análisis: despojo y abandono (ver sección siguiente). Pero, contrariamente a lo que se ha asumido desde algunos sectores en el debate público, no hay una muralla china entre el abandono y el despojo. La tierra de muchos desplazados nunca pasó a manos del perpetrador, pero tampoco regresó a las de la víctima, por diversas razones. ¿En qué sentido se diferencia esto del despojo? No se trata de una simple pregunta retórica; podría haber diferencias relevantes. Mientras que Ibáñez et al. (2006) y Garay et al. (2011) explícitamente incluyen en sus cálculos el despojo y el abandono con pérdida de tierras, los otros reportes no son tan claros al respecto. 


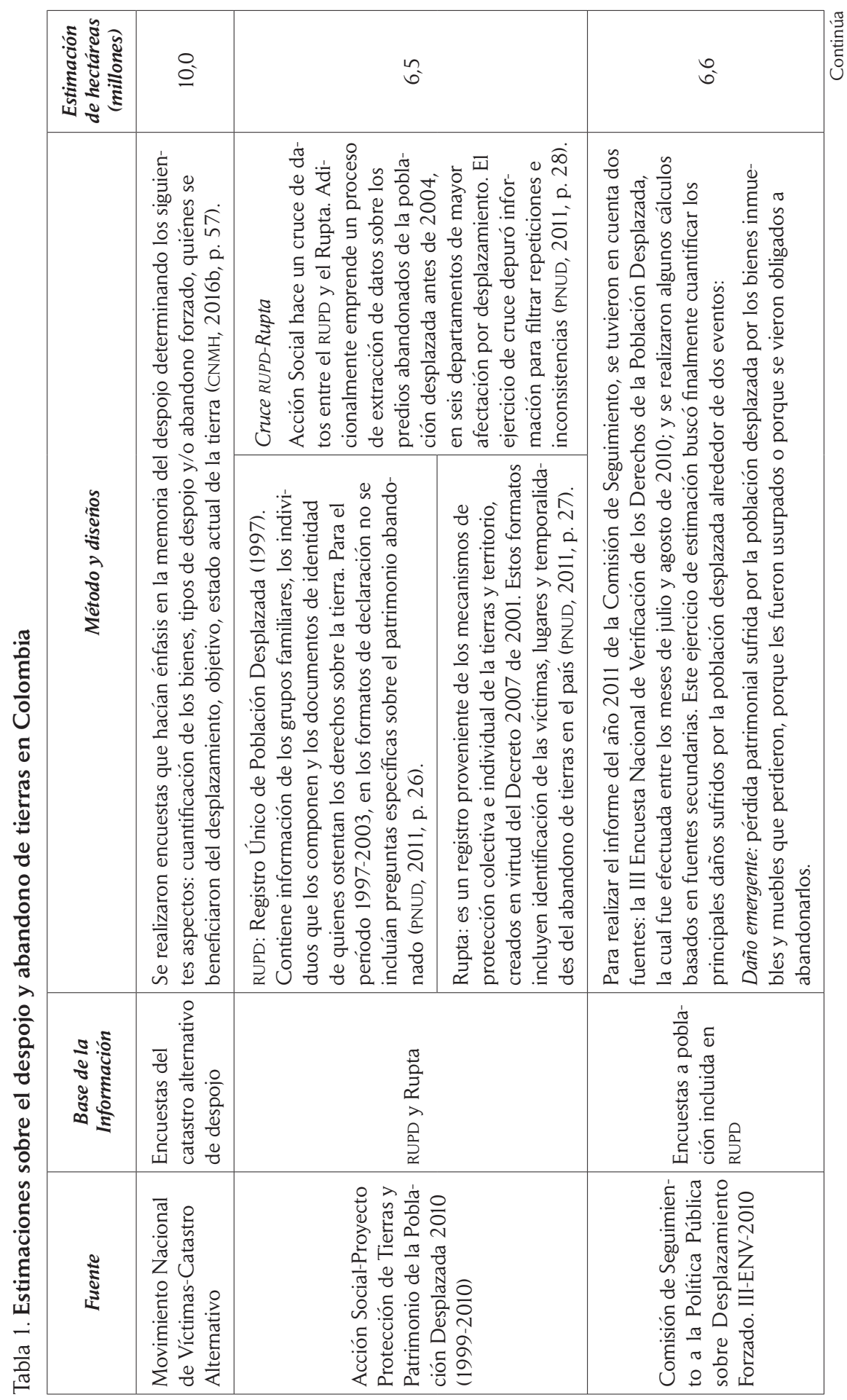

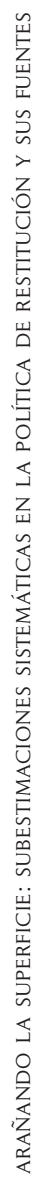




\begin{tabular}{|c|c|c|c|c|c|}
\hline 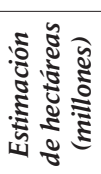 & & $\stackrel{q}{f}$ & $\nabla$ & $\hat{i}$ & $\ddot{m}$ \\
\hline 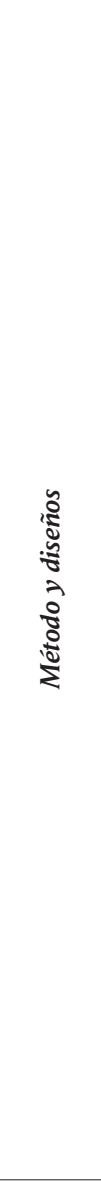 & 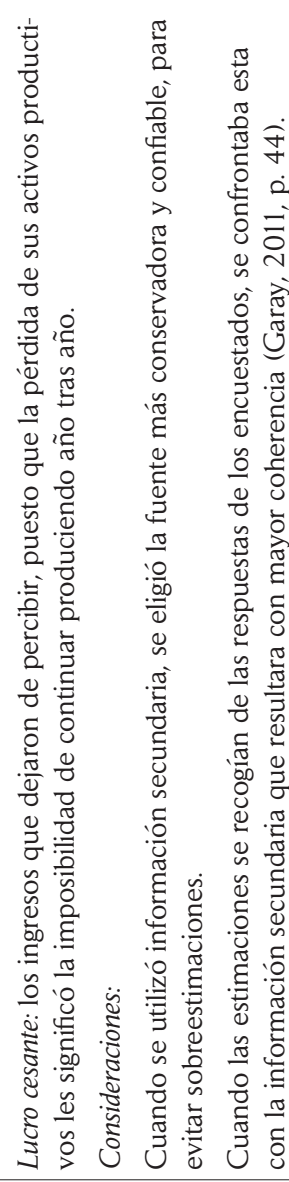 & & & & 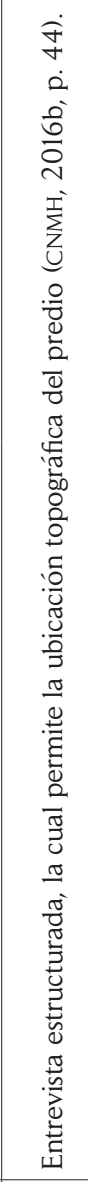 \\
\hline 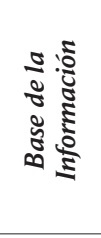 & & 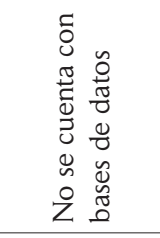 & 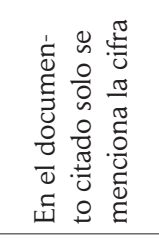 & 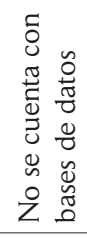 & 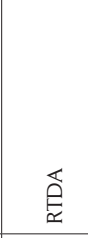 \\
\hline 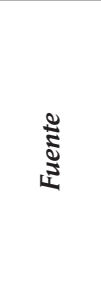 & & 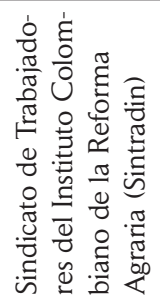 & 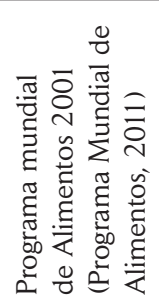 & 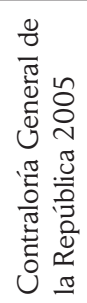 & 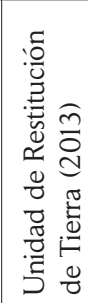 \\
\hline
\end{tabular}




\begin{tabular}{|c|c|}
\hline 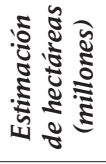 & $\stackrel{\simeq}{=}$ \\
\hline 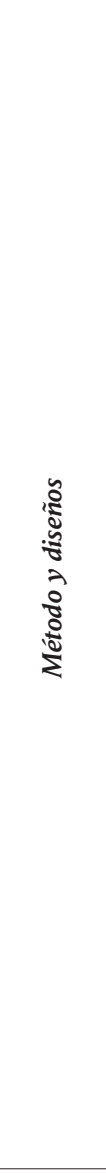 & 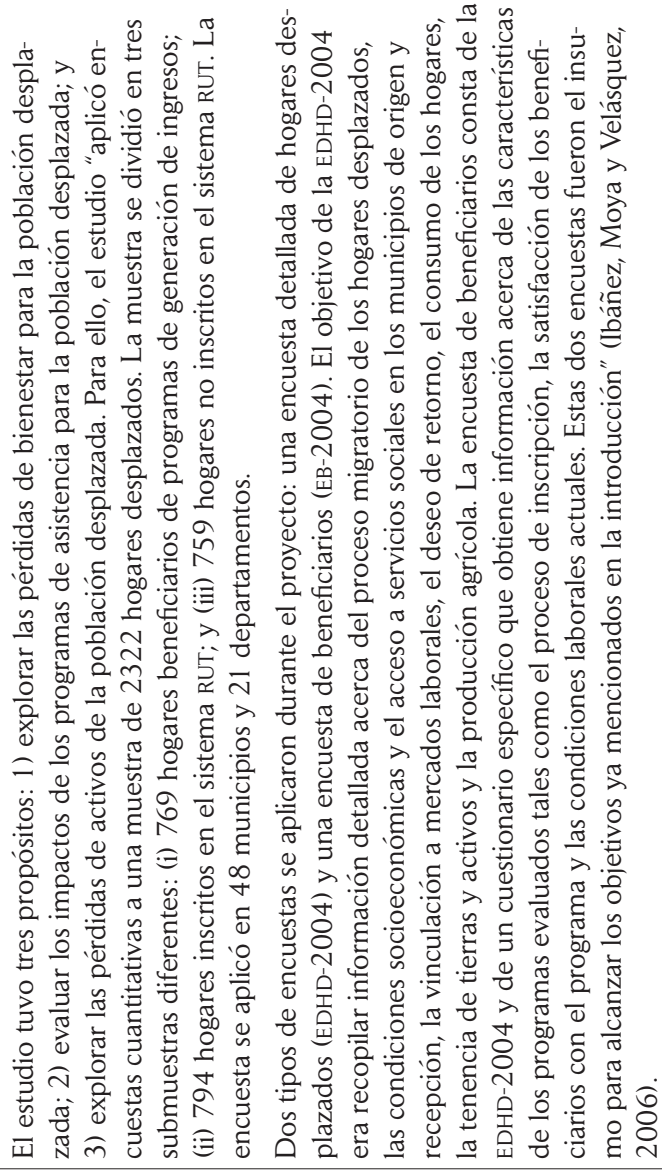 \\
\hline 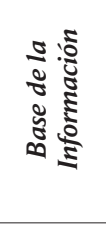 & 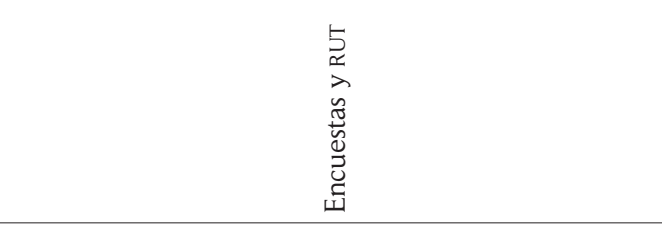 \\
\hline 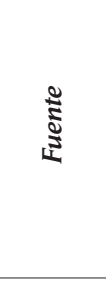 & 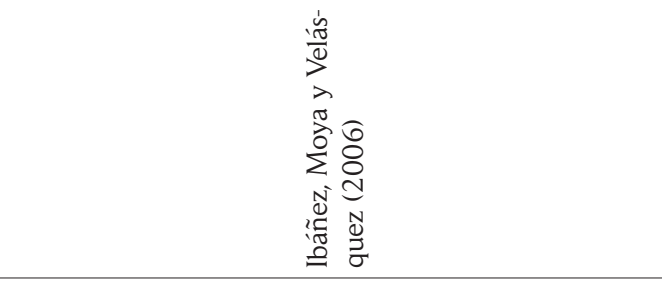 \\
\hline
\end{tabular}


Como fuere, adoptar una u otra cifra incidirá decisivamente sobre la valoración de las políticas relacionadas con el problema de la desposesión, así como del estado actual de sus víctimas. Por eso, no es casual que el tema haya entrado a la agenda del debate público y, en particular, de la evaluación de la política de restitución. Nunca se trazaron metas explícitas para la restitución, y esto creó las condiciones para que las cifras se cambiaran al calor de la coyuntura, generando incentivos además para ajustar las metas a las realizaciones. Por ejemplo, Ricardo Sabogal, director de la URT, ofreció en 2013 un estimativo de 2000000 de hectáreas despojadas (El Tiempo, 28 de abril de 2013) y el Conpes 3712 de 2011 estimó en 360000 las reclamaciones que recibiría el gobierno de parte de potenciales beneficiarios de la política. Pero en febrero de 2016 Sabogal ya había bajado el cálculo a 130000 solicitudes (Semana, 12 de febrero de 2016). En ningún momento se supo con claridad de dónde salía una u otra cifra. Otros, en cambio, han criticado la metodología o el quehacer de la política de restitución sobre la base de su lentitud o marginalidad relativa al tamaño del problema (ver, por ejemplo, Forjando Futuros, 2014). Por desgracia, muchos de los debates relevantes han quedado sin saldar debido a los complejos problemas relacionados con la construcción de cualquier estimativo (fuentes, métodos, conceptos).

La situación se vuelve peor, aunque no más sorprendente, debido a la ausencia de cualquier conteo oficial verosímil de colombianos que perdieron tierra en el curso del conflicto armado. El Estado no ha hecho un esfuerzo serio por medir el número de despojados (en contraste con el de desplazados, que sí tiene una contabilidad verosímil). La principal base de datos sobre victimización, el RUV ${ }^{4}$ solamente comenzó a incluir despojados desde 2012, 5 pero esa categoría en realidad nunca arrancó y al día de hoy incluye únicamente cerca de 5700 eventos de despojo o abandono, que afectaron a 5187 personas. ${ }^{6}$ De manera más general -a menos de que se pudiera hacer un sondeo con un marco muestral adecuado, ejercicio que enfrentaría numerosos problemas técnicos- el

4 Registro Único de Víctimas, http://rni.unidadvictimas.gov.co/RUV

5 De acuerdo con los datos abiertos de la Unidad de Víctimas, el registro de caso de despojo y abandono de tierras más antiguo corresponde al año 2012.

6 Reporte con corte del $1^{\circ}$ de mayo de 2017. Registro Único de Víctimas, http://rni.unidadvictimas.gov.co/RUV 
problema metodológico central es que las bases de datos de despojo y/o abandono son en general muestras de conveniencia. ${ }^{7}$ Estas muestras -que no son ni censos ni muestras aleatorias - tienen un gran valor para muchos ejercicios, pero no para hacer estadística inferencial (Freedman, 2010), y pueden adolecer tanto de severas subestimaciones (al no incorporar, por ejemplo, muchos casos que no han llegado al conocimiento de la agencia que construye la base) como de sobreestimaciones también potencialmente grandes (cuando, por ejemplo, se reportan casos que en realidad no corresponden al fenómeno estudiado). ${ }^{8}$

¿Cómo solucionar el problema? Aquí tomamos el camino de construir un estimativo local, es decir, de centrarnos en un número pequeño de municipios (en este caso cinco) y tratar de evaluar a partir de los datos disponibles el número de personas que perdieron su tierra durante el conflicto. Proceder así tiene algunas desventajas. La más obvia es que los resultados no se pueden generalizar. Pero a la vez tiene ventajas claves. El método que ha terminado siendo aceptado como el estándar más alto para poder hacer estimativos del tamaño de diferentes fenómenos violentos (Ball, 2008; Ball et al., 2007) es cruzar al menos tres muestras de conveniencia y someterlas a un MSE (multi-system estimation). Aunque esto en principio se podría hacer a nivel nacional, necesitaría de un complejo proceso de acuerdos entre organizaciones sociales, movimientos de víctimas y agencias del Estado, que por el momento no parece estar en la agenda. Además, quedarían pendientes algunos problemas que son algo complicados de resolver en el nivel local. ${ }^{9}$ Adicionalmente, si se tiene un buen conocimiento cualitativo del fenómeno del despojo en los municipios en los cuales se hace el estimativo, entonces se puede valorar mejor la plausibilidad de los resultados, así como explicarlos de manera más completa. En este caso particular, hemos elegido aplicar un ejercicio cuantitativo (MSE) a municipios que podrían considerarse como 'los casos menos probables'; es decir, hacemos estimaciones en municipios en los que en teoría no se deberían encontrar grandes problemas en los

7 Salvo potencialmente el de Garay et al., si su marco muestral permitiera recoger de manera representativa los casos de despojo y/o abandono con pérdida de tierras.

8 Y estos reportes erróneos no necesariamente son maliciosos. Por ejemplo, podría haber información incompleta o errónea por parte de quien reporta.

9 Como establecer los pareos de los casos entre las diversas bases. 
conteos, debido a que han estado entre los primeros atendidos por las políticas de restitución, y algunos han sido objeto de la consideración concentrada y consistente del Estado, de programas del sector privado y de ONG nacionales e internacionales. Es el caso de los municipios de San Onofre, Ovejas, El Carmen de Bolívar y María la Baja, que comprenden la región de los Montes de María entre Sucre y Bolívar; al igual que el caso de Chibolo en el departamento del Magdalena. ${ }^{10}$ Allí los procesos de microfocalización iniciaron desde el año 2013 (URT Bolívar, 2014; URT Magdalena, 2014; URT Sucre, 2014). Adicionalmente, en estos territorios se encuentra la intervención de agencias estatales, como el difunto Incoder, y toda la institucionalidad de la Ley 1448 (ver el caso de Chibolo: Pino, 2013). Por otro lado, la región montemariana se ha convertido en un foco de atención para un sinnúmero de organizaciones de la sociedad civil entre las que se rescatan: Codhes, Movice, Corporación Nuevo Arco Iris y la Fundación Semana. Muchos de estos proyectos, además, cuentan con apoyo y financiamiento extranjero a través de agencias de cooperación internacional, como la USAID y el BID-Fomin (De los Ríos, 2011; ILSA, 2012; Lefkaditis y Ordóñez Gómez, 2014; Semana, abril de 2016; ANUC y Corporación Nuevo Arco Iris, 2011).

Utilizando este diseño, presentamos aquí el siguiente resultado: en los cinco municipios considerados en nuestro texto, el déficit de cubrimiento de la política de restitución fue de 9 a 25 (es decir, de 1 identificado por cada 9 víctimas a 1 identificado por cada 25). Dicho en otros términos, la subestimación de tierras perdidas, y familias victimizadas por ello, por parte del Estado, es muy grande. El número real probablemente se debería contar no por las decenas de miles, sino por los cientos de miles o incluso por millones. Y, por consiguiente, la política de restitución es apenas un primer paso, positivo y necesario, pero preliminar, para enfrentar la pesada herencia de la guerra.

Como toda solución metodológica, esta tiene sus límites. En el marco de este primer ejercicio exploratorio, hemos escogido cinco municipalidades (Chibolo, El Carmen de Bolívar, San Onofre, Ovejas y María la

10 Igualmente, es importante indicar que, además de las circunstancias intrínsecas de cada municipio elegido para aplicar el estimativo, la selección de los casos atendió a los intereses del proyecto de donación al cual está vinculado este artículo como un producto de dicha investigación. 
Baja) de la costa Atlántica, y, por consiguiente, tratamos de manera casi exclusiva al despojo paramilitar. Por consiguiente, no pretendemos decir nada aquí sobre atribuciones; nuestro foco de atención es magnitud y cubrimiento. Hay preguntas también sobre la capacidad de generalización del ejercicio. Por supuesto, que en cinco casos se encuentre que la política de restitución tiene un pobre cubrimiento no quiere decir que sea así en todas partes. Sin embargo, los hallazgos sí son un indicio relevante de que algo anda mal en cuanto al cubrimiento, y sugieren verosímilmente que este podría ser un problema que no se restringe a los municipios estudiados aquí. Si en los cinco municipios escogidos se encontró que el déficit de cubrimiento era notable, eso da indicios serios de que podría ser así en general. Más aún cuando se identifican los mecanismos que explican ese déficit gracias al diseño explicado anteriormente. Por lo tanto, no estamos concentrándonos aquí en casos en los que uno esperaría que la política no funcionara. Por el contrario, se trata de 'casos menos probables' de subestimación: si la política ha fracasado en proveer un cubrimiento suficiente aquí, se puede esperar que tampoco tenga éxito en otras partes.

La exposición procede en el siguiente orden. Comenzamos con una revisión de la literatura sobre el despojo. Esta contiene importantes avances: definiciones del fenómeno, tipologías de las clases de despojo, identificación de sus protagonistas, estimativos de la magnitud del fenómeno. Contrastamos estos análisis con lo que se ha dicho sobre la restitución. Pero desde las definiciones mismas nos encontramos con dificultades conceptuales y metodológicas tanto para la estimación como para el análisis del fenómeno. La tierra puede concentrarse por diversas vías, legales e ilegales, y no conduce a buenos resultados meter todas estas rutas en el mismo saco del despojo. ${ }^{11}$ Consideramos las varias maneras en las que podría refinarse la definición, ${ }^{12}$ y proponemos una solución que es compatible tanto con lo estipulado en la ley como con las cuantificaciones de Ibáñez et al. (2006) y Garay et al. (2011). Después

11 Por supuesto, se puede considerar como un mal social la concentración adicional de la propiedad de la tierra en un país tan desigual como Colombia, pero eso ya es otro problema.

12 Ellas en general aumentarían el número de despojados en relación con la definición legal vigente. No analizamos aquí los efectos de una posible redefinición. 
presentamos los estimativos. Describimos nuestros datos, y analizamos la magnitud de la subestimación del número de despojados por parte del Estado. A renglón seguido, nos concentramos en las dinámicas que tienden a generar subestimación en los conteos por parte de la política de restitución, tal como está diseñada. En las conclusiones, sugerimos nuevas rutas de análisis y ajustes en la política.

\section{La literatura}

Revisamos en esta sección la literatura directamente relevante para la estimación del despojo y para la potencial comprensión de fuentes de sub o sobreestimación de su magnitud. La dividimos en cuatro partes. En primer lugar, aquella que estima el despojo y lo caracteriza. En segundo lugar, hacemos un recordatorio de lo que dice la Ley 1448 acerca de las categorías de víctimas que pueden aspirar a la restitución. En tercer lugar, revisamos las dificultades conceptuales que enfrenta el analista que quiera cuantificar el despojo en Colombia. En cuarto lugar, hacemos una revisión de lo que se ha dicho sobre la restitución.

\subsection{Despojo: su magnitud y dinámicas}

La tabla 1 sintetiza los resultados de las investigaciones orientadas a estimar cuántos despojos y abandonos se produjeron durante el conflicto armado colombiano. ${ }^{13}$ También hay investigaciones que se concentran en los mecanismos utilizados para el despojo. Quizá la más conocida sea la de la Superintendencia de Notariado y Registro (2011b), que construye la siguiente tipología sobre el despojo: material (la víctima sigue siendo el titular, pero hay una ocupación por parte del despojador), administrativo (actos administrativos del Incora/Incoder) y jurídico (ventas irregulares y viciadas).

13 El RUPD hace un registro desde el año 1997 y desde el año 2004 incluye en sus instrumentos el tema de patrimonio perdido por los desplazados; el Rupta viene haciendo el registro desde el año 2001; el trabajo de Ibáñez et al. (2006) aplicó la encuesta en 2004; y el trabajo de Garay et al. (2011) aplicó la encuesta entre julio y agosto de 2010. 
Respecto a esta última categoría, el despojo por la vía jurídica, García y Vargas (2014) proponen el concepto de transacciones asimétricas, el cual se subdivide a su vez en dos. Por un lado, aquellas que tienen como principal recurso el uso de la violencia para conducir al abandono de las tierras por parte de los campesinos, para luego realizar transacciones fraudulentas y legalizar el despojo. Por otro lado, aquellas que se derivan del uso de información privilegiada y del poder económico de compradores interesados en la tierra. En esta ruta, los mecanismos de concentración vía mercado llegan después de que se haya producido la expulsión coercitiva de los campesinos de sus predios. En efecto, es posible, como lo destaca Uribe (2014), que los actores involucrados en una y otra acción (expulsión y acumulación potencialmente ilegal pero no violenta) no estén orgánicamente conectados.

Ciertamente, los actores del despojo pueden variar según las dinámicas sociales que los hayan generado (Gutiérrez, 2014), lo cual subraya el hecho de que el despojo no constituyó un fenómeno impulsado por actores armados completamente separados de la sociedad, sino más bien por complejas redes en las que han participado desde grupos armados hasta diversos actores sociales e institucionales. En la tónica de identificar las dinámicas sociales subyacentes al despojo, hay investigaciones que dan cuenta de las alianzas y conexiones del nivel nacional y regional (Salinas y Zarama, 2012; Gutiérrez y Vargas, 2016; Corporación Jurídica Yira Castro, 2011; Céspedes, 2010), así como del nivel local (Quinche, 2016), que se construyeron alrededor del despojo y que permiten observar los tipos de involucramiento que tuvieron allí agencias estatales, actores políticos y empresariales, y élites rurales. Esto incluye algunos casos de estudios emblemáticos, como el del municipio de Chibolo (Magdalena), en el cual el jefe paramilitar Rodrigo Tovar alias 'Jorge 40' y el ganadero Augusto Castro 'Tuto Castro' se apoderaron de un variado número de propiedades a partir del uso de figuras administrativas del Incora/Incoder, como la caducidad administrativa, las revocatorias y las readjudicaciones, para implementar y legalizar el despojo en esta región (Quinche, 2016). También encontramos estudios sobre los casos de despojo de tierras de las comunidades de Curvaradó y Jiguamiandó (Franco y Restrepo, 2011; García y Vargas, 2014; Grajales, 2011; Thomson, 2011), donde una serie de empresas palmeras con nexos paramilitares (Castaño), en un contexto 
de desplazamiento forzado, se aprovecharon de las tierras que pertenecían a los consejos comunales y con ayudas financieras por parte del Estado emprendieron sus proyectos agroindustriales. En el Pacífico colombiano también se tiene un escenario en el cual las disputas violentas por la apropiación de tierras y recursos se deben a los intereses económicos que están en juego entre actores ilegales, armados y el Estado: la producción de cocaína y las rutas del narcotráfico, la explotación minero-energética, la proliferación del monocultivo de palma y la especulación frente a la construcción de infraestructura vial y portuaria (Codhes, 2013).

\section{2. ¿Qué dice la ley?}

La ley dispuso como medida de reparación integral la restitución material y jurídica de los predios que fueron abandonados o despojados con ocasión al escenario del conflicto armado. Este tipo de reparación tiene como elemento principal que la víctima demuestre su relación con la tierra. Así, el artículo 75 establece como sujetos del derecho a la restitución a aquellas personas que en su condición de propietarios, poseedores de predios u ocupantes de baldíos, tuvieron que abandonar sus tierras o fueron despojadas de ellas a partir de enero de 1991. De igual manera, la ley toma en cuenta diversos procesos de pérdida de la tierra, definiendo así el abandono y el despojo de tierras en su artículo 74 :

- Abandono forzado: se entiende como la situación temporal o permanente a la que se ve abocada una persona forzada a desplazarse, razón por la cual se ve impedida para ejercer la administración y explotación de su predio debido al desplazamiento ocurrido después de 1991.

- Por despojo de tierras se entiende la acción por medio de la cual, aprovechándose de la situación de violencia, se priva arbitrariamente a una persona de su propiedad, posesión u ocupación, ya sea de hecho, mediante negocio jurídico, acto administrativo, sentencia, o mediante la comisión de delitos asociados a la situación de violencia. En su artículo 77, la Ley 1448 complejizó aún más el panorama de pérdida de la tierra al incluir algunas presunciones legales y de derecho de ciertos actos jurídicos, administrativos y judiciales, con el 
fin de garantizar el derecho a la restitución de los solicitantes, con lo cual se reconoce, entre otras cosas, que el despojo utilizó distintos mecanismos para apropiarse de la tierra, así mismo necesitó la participación de actores legales e ilegales en la consecución de sus fines.

- La presunción de derecho de ciertos contratos: cuando las víctimas transfieren su derecho real, la posesión u ocupación a personas condenadas que hacen parte de grupos al margen de la ley o bien sea que estos últimos hayan actuado a través de terceros.

- La presunción legal de ciertos contratos: salvo prueba contraria se asume que hubo ausencia de consentimiento en los siguientes negocios jurídicos:

- Los contratos de compraventa que ocurrieron durante los años de violencia generalizados, de desplazamiento forzado o de graves violaciones a los derechos humanos, o en aquellos inmuebles donde se haya solicitado las medidas de protección colectivas e individuales relacionadas con la Ley 387 de 1997, excepto en los casos en los que la transferencia cuenta con la autorización de la autoridad competente.

- La compra de inmuebles colindantes a aquellos predios que habían sido despojados, lo cual tuvo como consecuencia la concentración de la propiedad de la tierra en una o más personas, o si por estos contratos y concentraciones se produjo una alteración significativa de los usos de la tierra, como la sustitución de agricultura de consumo hacia los monocultivos, la minería o la ganadería extensiva.

- Que el negocio se haya efectuado con personas extraditadas por narcotráfico o delitos conexos.

- En los casos en los que el valor formalmente consagrado en el contrato sea inferior al 50\% del valor real de los derechos al momento de la transacción.

Cuando no se logren desvirtuar los anteriores hechos, el negocio jurídico será reputado de inexistente.

- De la misma manera existen presunciones legales sobre ciertos actos administrativos, planteando la nulidad de tales actos cuando contrarían 
los derechos de las víctimas a su restitución. En este sentido, serán nulas las sentencias de pertenencia o resoluciones del Incoder cuando la víctima hubiere demostrado la propiedad, posesión u ocupación y posterior despojo del inmueble.

- Finalmente, existen presunciones sobre el debido proceso de decisiones judiciales, lo cual indica que no puede negársele la restitución al solicitante aun cuando el predio en cuestión haya sido otorgado o transferido a favor de un tercero mediante una sentencia judicial.

En síntesis, la ley establece las definiciones de los potenciales beneficiarios de la restitución. Vale la pena destacar dos conclusiones aquí. Primero, es claro que la ley excluye explícitamente a algunas categorías de potenciales víctimas: por ejemplo, aquellos que perdieron sus tierras antes de 1991, o los que apenas eran tenedores. ${ }^{14}$ Tampoco incluye pérdidas cruciales para la economía campesina (menaje doméstico, animales de granja, aves de corral, entre otros). A la vez, reconoce explícitamente -como había que hacerlo- que el despojo no se limitó al puro uso de la coerción, sino que, como en la categorización de la Superintendencia de Notariado, también incluyó actos jurídicos y administrativos. Es decir, incluye un amplio abanico de afectaciones a los derechos de propiedad de las víctimas. Esto nos lleva al siguiente acápite.

\subsection{Problemas conceptuales y metodológicos}

Como se ve en la tabla 2, construir una definición de despojo es difícil. Esto no es casual: los actos de fuerza frecuentemente van de la mano de la capacidad de incidir sobre los parámetros de definición, precisamente porque quienes los llevan a cabo tienen poder.

En particular, hay tres aspectos de las definiciones de despojo resumidas en la tabla 2, incluida la legal, que hacen ambiguo el concepto. Primero, su naturaleza arbitraria; segundo, su situación de permanencia; tercero, su relación con la voluntad del perpetrador. Por ejemplo, la Comisión Nacional de Reparación y Reconciliación (2009) define el

14 La ley solo concibe como potenciales beneficiarios de la restitución a: propietarios, poseedores y ocupantes de predios (Ley 1448, artículo 75). 
abandono como una acción que "implica la suspensión del uso, disfrute, acceso y posesión de cosas o incluso de derechos [...] es decir la privación temporal o permanente de las cosas que se tiene y disfruta. El abandono implica también el desplazamiento del titular del lugar y del territorio en el que se encuentra su bien" (p. 25). Por su lado, el despojo se concibe como el acto de "privar a alguien de lo que goza y tiene, desposeerlo de ello con violencia [...] es un acto violento o clandestino por el cual uno es privado de una cosa mueble o raíz que poseía o del ejercicio de un derecho". El despojo, a diferencia del abandono, exigiría entonces una intención manifiesta de robo, expropiación, privación, enajenación de un bien o de un derecho por parte de un tercero (CNRR, 2009, p. 25). Pero es claro que el abandono también puede implicar, y ha implicado masivamente, el uso de la violencia, así como de la voluntad por parte del perpetrador. Con respecto de los límites temporales, ¿cuál es la frontera adecuada? Si alguien pierde su bien durante 30 años, y después vuelve a manos de sus herederos, ¿eso fue abandono o despojo?

Dificultades análogas se presentan cuando la línea divisoria se construye sobre la voluntad del perpetrador. Si el 'despojo activo' es el "acto planeado y consciente de quitar la tierra a alguien, con el fin de redistribuir los derechos de propiedad entre otros agentes [...] el agente despojador, o (si) alguno de sus representantes, intenta explícitamente apropiarse del predio y la víctima lo abandona, porque alguien le exige entregárselo" (Gutiérrez, 2014, p. 45), no solamente la voluntad, sino la transferencia de los derechos de la tierra al perpetrador o a terceros puede volverse el criterio para la identificación del despojo (González, 2013). Pero la separación sigue siendo imperfecta, pues hay muchos abandonos en los que finalmente la tierra es transferida a terceros (por ejemplo, cuando predios abandonados ingresan al mercado, como lo reporta Uribe en 2014). Una definición alternativa de González - “La distinción para la víctima está dada por la capacidad de ejercer la libre disposición del bien o la imposibilidad de hacerlo por la continuidad de la amenaza a la vida e integridad o, de otro lado, por la usurpación de hecho o mediante artificios legales" (2013, p. 7) - captura así mismo tanto situaciones consideradas regularmente de abandono como de despojo. 


\begin{tabular}{|c|c|c|c|c|}
\hline 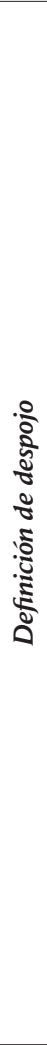 & 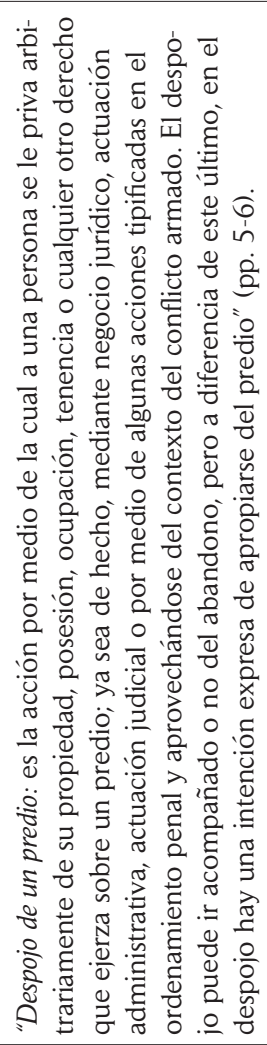 & 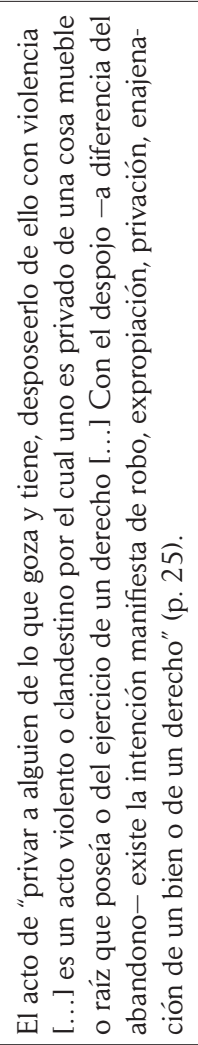 & 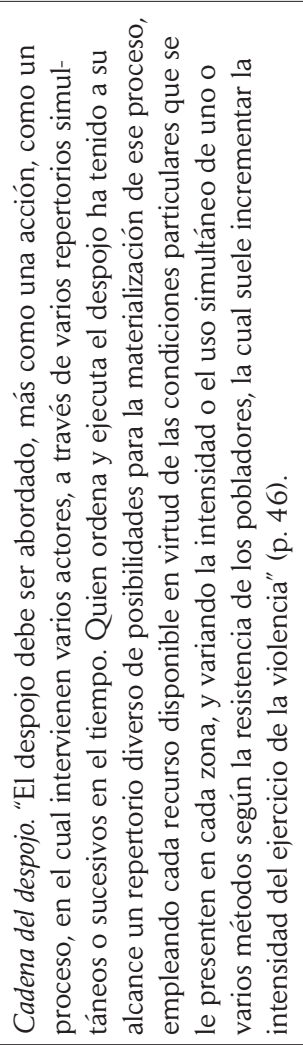 & 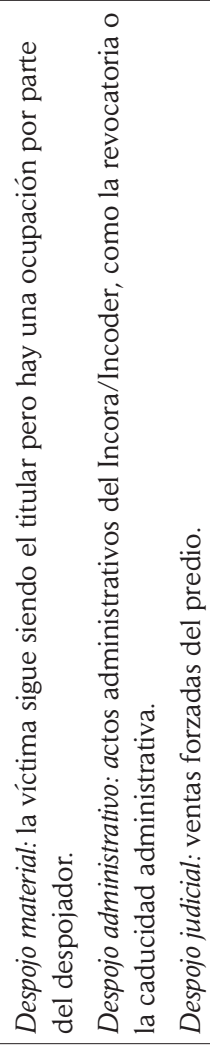 \\
\hline 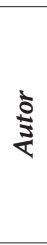 & & 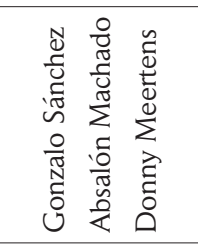 & 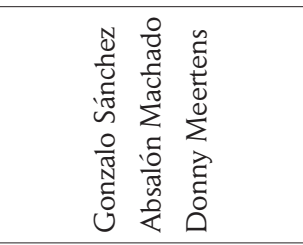 & \\
\hline 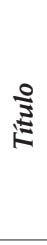 & 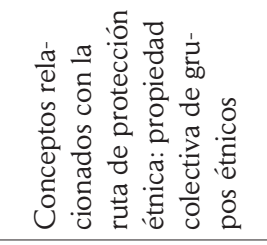 & 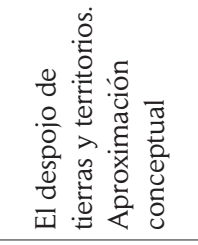 & 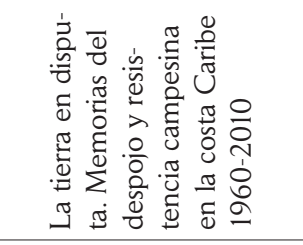 & \\
\hline 住 & ஓे & 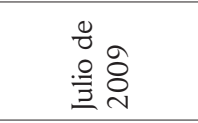 & $\overline{\text { N }}$ & $\stackrel{\sim}{\sim}$ \\
\hline 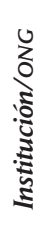 & 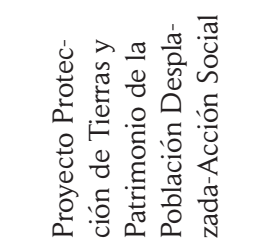 & 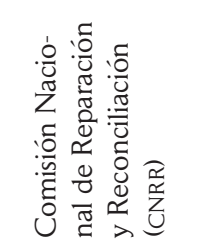 & 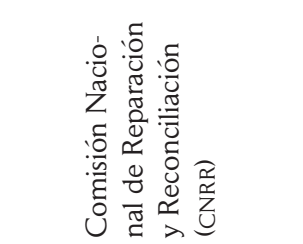 & 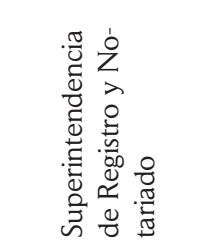 \\
\hline
\end{tabular}




\begin{tabular}{|c|c|c|c|}
\hline 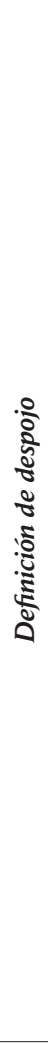 & 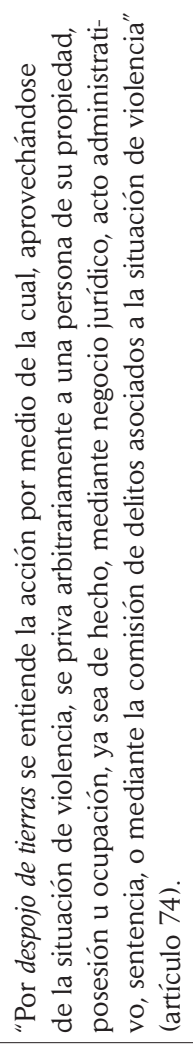 & 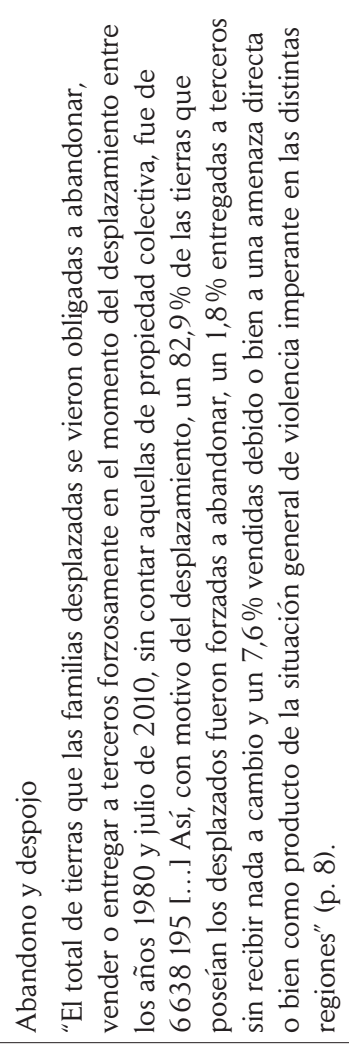 & 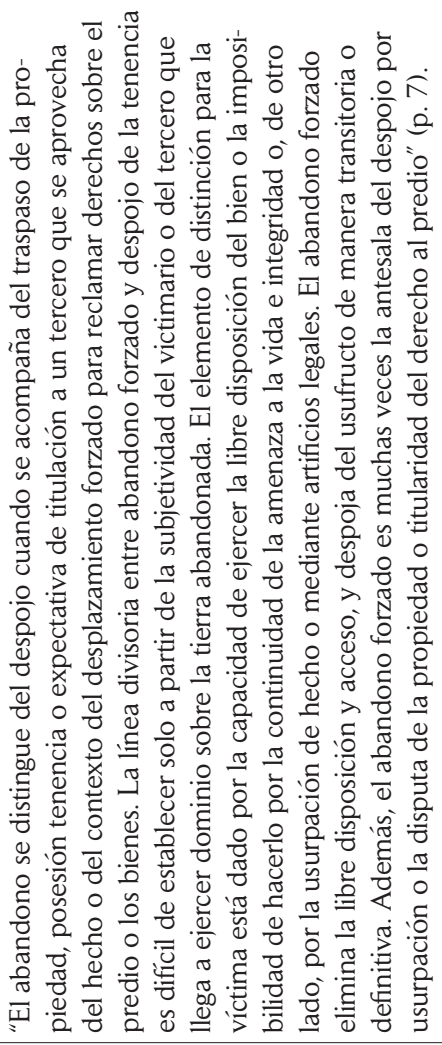 \\
\hline$\frac{\grave{t}}{\grave{t}}$ & & 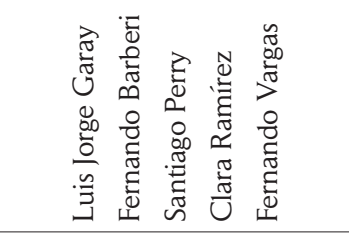 & 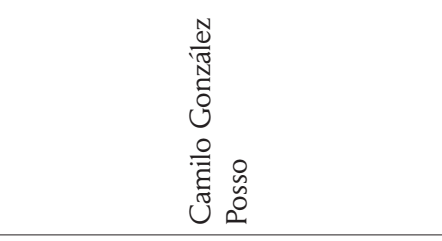 \\
\hline$\underset{⿱ 乛}{\mathbb{Z}}$ & & 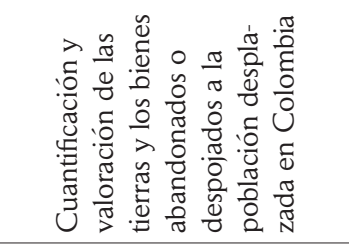 & 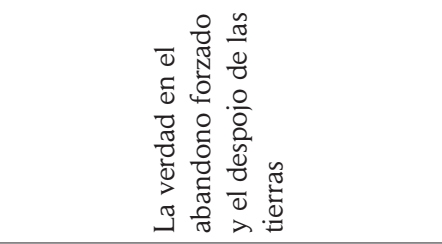 \\
\hline 吝 & $\approx$ & 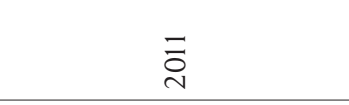 & $\stackrel{n}{\sigma}$ \\
\hline 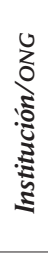 & 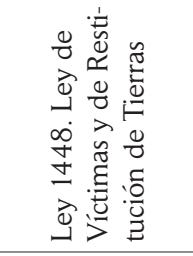 & 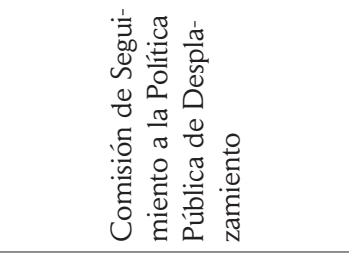 & \\
\hline
\end{tabular}


En síntesis, la situación es la siguiente. Tenemos una noción intuitiva de despojar, que corresponde a la de diccionario de "privar a alguien de lo que goza y tiene ${ }^{\prime \prime} .{ }^{15}$ Esta noción involucra la voluntad del perpetrador, y está bien que sea así. La correlativa de abandonar es "dejar solo algo o a alguien alejándose de ello o dejando de cuidarlo". ${ }^{16}$ Podría sonar cínico hablar de abandonos en el contexto colombiano, pero la realidad es que fueron masivos, cuando, por ejemplo, se produjeron combates en la región, o había amenazas generalizadas contra la población, o simplemente la economía regional sufrió desestabilizaciones lo suficientemente significativas por el conflicto armado que las víctimas decidieron irse con lo que podían cargar. El abandono, entonces, se refiere a la decisión por parte de la víctima de dejar su predio.

El problema, pues, es que las categorías de despojo y abandono hablan de dos cosas distintas. El despojo se refiere a la decisión del perpetrador. El abandono, a la decisión de la víctima. Por consiguiente, puede haber $-\mathrm{y}$ hay- un área de intersección no desdeñable entre las dos categorías. De hecho, la secuencia primero abandono y después despojo es completamente natural. Por ejemplo, el señor Pérez abandona su predio porque su municipio se ha vuelto terriblemente peligroso, y después el grupo armado que está allí, al notar que está disponible, se lo transfiere a un tercero. Nótese que todo esto explica por qué las diferentes categorizaciones de despojo, incluyendo la legal, incorporan a la definición la voluntad del perpetrador y frecuentemente están modificadas por términos como 'arbitrariamente'. Pero a la vez muestra por qué no se puede tratar al abandono y al despojo como dos compartimientos estancos.

Las implicaciones de estos problemas conceptuales sobre los ejercicios cuantitativos son obvias. Operacionalizar criterios que involucran la voluntad del perpetrador o la arbitrariedad de la acción simplemente no es posible. Más aún cuando en Colombia las bases de datos y el registro sobre el abandono y despojo se han construido con diferentes criterios, lo que ha dificultado su triangulación (Gómez, Sánchez y Vargas, 2015, p. 271). Adicionalmente, la recolección de información depende de los datos que lleguen a suministrar las víctimas, lo cual tiene como consecuencia

\footnotetext{
15 RAE, http://dle.rae.es/?id=DO2oYrf

16 RAE, http://dle.rae.es/?id=01 yxXv6
} 
que exista un considerable subregistro de la información (CNMH, 2016a); volveremos al asunto más adelante.

Cualquier cuantificación debe concentrarse, pues, en el concepto de pérdida de predio en el contexto del conflicto armado, es decir, de desposesión: un evento en el cual los principales derechos sobre un predio fueron usurpados a su titular durante un período significativo de tiempo. Esta ampliación del concepto soluciona varios problemas. No se necesita tener acceso a la voluntad del perpetrador o de la víctima para establecer el conteo. Hay registros sobre los hechos, así compararlos sea difícil. El concepto es plenamente compatible con la definición legal -que precisamente lo que hace es considerar el menú de afectaciones de los derechos de propiedad que podrían ser reparados con la restitución-y con otras que se han propuesto con anterioridad en sendos ejercicios cuantitativos. Quedan en pie algunas ambigüedades importantes - principales derechos, la arbitrariedad implícita en compras ilegales, período significativo de tiempo-, pero eso también afecta a otras definiciones y probablemente sea inevitable. Volvemos al tema en las conclusiones.

\subsection{La restitución}

La extrema asimetría, el carácter brutal y las consecuencias devastadoras sobre las víctimas que acompañan el acto del despojo hacen explicable que la política creada para repararlo, o para reversar sus efectos, plasmada en la Ley 1448 de 2011, haya constituido un foco de atención.

Desde el punto de vista positivo, la restitución ha cambiado así sea parcialmente la forma como el Estado colombiano se dirige a las víctimas y a la sociedad civil respecto a las problemáticas del conflicto armado. En este cambio de dirección se han logrado ubicar nuevamente temas en la agenda política colombiana relacionados con la tierra y el conflicto armado, un debate que había estado relegado en años anteriores. Se creó la Unidad de Restitución, como una agencia que se desalinea de las dinámicas del poder local, lo que ha significado un paso hacia adelante en la prevención del despojo. En otras palabras, garantizar una burocracia técnica y especializada implica romper con las redes clientelistas que alimentó el paramilitarismo y otros actores armados para sus fines 
despojadores (Observatorio de Restitución y Regulación de los Derechos de Propiedad Agraria, 2013).

En la otra dirección, la lentitud del proceso de restitución y los problemas de seguridad de los solicitantes y líderes se han convertido en los principales puntos críticos de la implementación. Según el Observatorio de Restitución y Regulación de los Derechos de Propiedad Agraria (2013, 2016), el proceso de restitución basado en la resolución del conflicto por la tierra desde el ámbito judicial, caso a caso, es inviable, y demoraría miles de años en restituir los predios solicitados. A una apreciación similar ha llegado la fundación Forjando Futuros (2014) tras la revisión de las sentencias judiciales. De otro lado, el informe de Amnistía Internacional (2014) ha indicado el preocupante escenario de seguridad que afecta y pone en peligro a los solicitantes y líderes de restitución en sus distintos procesos. Amnistía indica además la demora en los tiempos como un factor que amenaza la viabilidad de la restitución, para lo cual recomienda ampliar el plazo de diez años de aplicación de la ley.

\section{Los estimativos}

Identificando estos límites conceptuales y metodológicos, junto a las dificultades de la política de restitución, procedemos a realizar el ejercicio exploratorio sobre la magnitud del despojo en los municipios que fueron presentados en la introducción. Aquí se quiere mostrar precisamente esos obstáculos conceptuales que dificultan la operacionalización del despojo y el abandono, y, por lo tanto, obstruyen el ejercicio de estimación de este fenómeno; así mismo, se expondrán los resultados que darán cuenta del preocupante subregistro en los conteos oficiales y del poco alcance que ha tenido la política de restitución en estos municipios que fueron considerados pilotos del proceso. Por ende, en esta sección presentamos nuestras bases de datos, los métodos utilizados y los estimativos. Los aspectos más técnicos se dejan para los anexos.

\subsection{Datos}

En este trabajo utilizamos seis fuentes de información principal: 
a) La base de datos del Registro Único de Predios Abandonados por la Violencia (Rupta): esta base de datos corresponde al registro en el cual el Incoder ingresa los predios abandonados por la violencia, de acuerdo con las declaraciones de las víctimas. Esta base, que se empezó a crear desde 1997, comprende más de 53000 registros para todos los municipios del país de eventos ocurridos desde 1950.

b) Una base de datos construida a partir de los fallos judiciales y que se encuentra a disposición del público en la página web de la Unidad de Restitución de Tierras, con sentencias proferidas entre enero de 2013 y diciembre de 2016 para los territorios de Chibolo, El Carmen de Bolívar, María la Baja y Ovejas.

c) Una base de datos de desplazamiento forzado creada por la Fiscalía de Barranquilla a partir de los casos a cargo de la fiscal Carmen Donado, que comprende un total de 281 casos para toda la costa Atlántica.

d) Una base de datos de casos de despojo y abandono que se elaboró a partir de los expedientes judiciales revisados en el Juzgado Primero Penal Especializado de la ciudad de Santa Marta desde el año 2016.

e) La base de datos del Observatorio de Tierras, elaborada a partir de las encuestas realizadas en 2014 con la metodología de muestreo para poblaciones ocultas respondent driven sampling (Heckathorn, 1997) a víctimas del despojo y abandono en municipios de la costa Atlántica y de Bogotá, para un total de 499 encuestados.

f) La base de datos de despojo y abandono en los municipios de interés, hecha a partir del trabajo de campo realizado para Codhes en febrero de 2017 y en el que se les realizó encuestas y entrevistas en profundidad a cerca de 50 víctimas de despojo y abandono en San Onofre, María la Baja y Santa Marta.

Todas estas son muestras de conveniencia. Y trabajar con los datos ofrecidos en estas bases implicó un esfuerzo de triangulación y limpieza de la información. Por ejemplo, en el Rupta hay varios casos en los que las personas registran como casos de despojo el robo de tierras por disputas con sus vecinos, situación que se excluye de las definiciones tradicionales de despojo y abandono, y que nosotros teníamos que sacar de nuestro análisis. Incluso, cuando se consideran bases de datos como la de la Fiscalía sobre despojo y abandono, se observan registros 
en donde se señala explícitamente que el predio fue dejado por el contexto de violencia generalizado, pero se clasifica el hecho como despojo. Nuevamente aquí la debilidad en la conceptualización termina siendo determinante para los conteos.

Teniendo en cuenta esto, a las bases de datos y principalmente al Rupta, se les efectúa un tratamiento previo en el que, de ser posible, se identifiquen aquellos predios en los que el dueño del derecho haya sufrido de despojo o abandono del predio de acuerdo con dos consideraciones principales:

- Que el declarante posea el derecho sobre el predio.

- Que haya dejado el predio por factores relacionados con la violencia del conflicto (víctima de masacre, desplazamiento, asesinato selectivo, entre otras).

Por lo tanto, no se tienen en cuenta las personas:

- Para las que no se posea información que permita dilucidar si cumplen las condiciones señaladas previamente.

- Que hayan invadido el predio ilegalmente.

- Que se encontrasen en proceso de adjudicación.

- Que arriendan o trabajan el predio.

- Que se encuentren en baldíos.

- Que pidan protección del predio por causas diferentes a la violencia (tales como disputas familiares, invasiones de vecinos).

Nótese que en todo el proceso de limpieza de información se intentaron eliminar diversas fuentes de sobreestimación del fenómeno.

\subsection{El 'multi-system estimation' (MSE)}

El MSE nació en el contexto de la ecología, y hace uso de principios ya desarrollados en los llamados métodos de captura y recaptura (Mooney y Swift, 1999). Se basa en un principio relativamente simple: comparar diversas muestras, no necesariamente aleatorias, a partir de cuántas unidades (pueden ser personas, objetos, animales) de una base se encuentran 
en la otra. Así, intuitivamente, se busca observar a los individuos durante varias recolecciones, de manera que, si se observan en estas recolecciones varias veces a los mismos individuos, entonces la población es pequeña. Por el contrario, si es difícil observar a los mismos individuos durante las diferentes muestras, entonces la población es grande. En general, el procedimiento para realizar el MSE es:

- Realizar un primer muestreo (o tener una primera base de datos) y marcar a los individuos.

- Hacer un segundo muestreo, marcar a los nuevos individuos y registrar cuántos de ellos fueron observados durante el primer muestreo.

- Hacer varios remuestreos.

- Una vez se tenga el conteo de individuos nuevos e individuos recapturados, se utilizan procedimientos estadísticos para estimar la población total.

\subsection{Los resultados}

Llevamos a cabo una estimación del número de despojos y abandonos con pérdida de tierras para cinco municipios, a saber: Chibolo, El Carmen de Bolívar, Ovejas, María la Baja y San Onofre. Sintetizamos los resultados y análisis en las tablas 3 y 4 . La tabla 3 contiene las siguientes columnas. Primero, el municipio donde se hizo el ejercicio. Después, el número de bases de datos que se usaron en él; recuérdese que para hacer un MSE se necesitan al menos tres bases. Luego, reportamos el total de casos únicos en todas las bases, es decir, quitando los cruces entre ellas; $y$, posteriormente, se registra el número de cruces. A continuación, proveemos el estimativo MSE en la forma de un número, junto con un intervalo formado por sumar y restar la desviación estándar. A renglón seguido, se ofrece en forma de porcentaje la probabilidad de captura, interpretada como la probabilidad de que un individuo particular sea capturado durante esa muestra. En la tabla 4, se reportan los cruces en las bases de datos. Sin embargo, se debe tener en cuenta que en algunos municipios la falta de cruces puede no deberse a que la población sea muy grande, sino a que el subregistro es tan grande que las bases de datos no logran capturar la verdadera situación de la población. Por consiguiente, en estos casos es 
necesario ser muy prudente con la interpretación de los resultados. En nuestro estudio, este es el caso particularmente para María la Baja. Por el contrario, los estimativos de Chibolo y San Onofre se encuentran en 'terreno sólido', corroborado también por amplia evidencia cualitativa.

La tabla 4, por otro lado, describe los casos atendidos y resueltos por medio de sentencia por parte de la Unidad de Restitución de Tierras (URT). A simple vista, se encuentra que las diferencias entre los estimativos de despojo de la tabla 3 y las solicitudes, y especialmente las sentencias, reportados por la URT son enormes. Por ejemplo, en San Onofre la URT no ha producido ninguna sentencia, mientras que los casos únicos de todas nuestras bases juntas suman 315 eventos, lo que, según el estimativo del MSE, arroja un número de 2300 casos aproximadamente (el límite inferior del intervalo de confianza). En María la Baja llegaron más de 300 solicitudes de restitución, que han producido hasta ahora 23 sentencias; nuestras bases de datos arrojan 359 casos únicos, lo que a través del MSE da un estimativo de al menos 2600 eventos. En Chibolo llegaron 417 solicitudes de restitución que han producido 2 sentencias. En nuestras bases encontramos 183 casos únicos, lo que arroja un estimativo MSE de al menos 568 casos. En Ovejas la diferencia entre solicitudes de restitución y el estimativo no es grande, pero sí lo es, y abismal, entre el número de sentencias y el de solicitudes. En El Carmen de Bolívar la diferencia entre el número de solicitudes recibidas y el estimativo es de 1 a 7 , y entre las sentencias y el estimativo de 1 a 130 .

Tabla 3. Resultados MSE de los municipios estudiados

\begin{tabular}{|l|c|c|c|c|c|}
\hline \multicolumn{1}{|c|}{ Municipio } & Bases & $\begin{array}{c}\text { Total de casos } \\
\text { únicos }\end{array}$ & $\begin{array}{c}\text { Número de } \\
\text { cruces }\end{array}$ & Estimativo & $\begin{array}{c}\text { Probabilidad } \\
\text { de captura }\end{array}$ \\
\hline Chibolo & 5 & 183 & 29 & $696+-128(729)$ & $16 \%$ \\
\hline El Carmen de Bolívar & 4 & 1240 & 19 & $\begin{array}{c}19163+-4261 \\
(22020)\end{array}$ & $4 \%$ \\
\hline Ovejas & 4 & 197 & 6 & $2541+-1003$ & $11,23 \%$ \\
\hline María la Baja & 4 & 359 & 2 & $8538+-5910$ & $4 \%$ \\
\hline San Onofre & 3 & 315 & 8 & $3529+-1193$ & $4 \%$ \\
\hline
\end{tabular}

Fuente: cálculos de los autores. 
Tabla 4. Solicitudes y sentencias de restitución en los municipios estudiados

\begin{tabular}{|l|c|c|c|c|c|}
\hline \multicolumn{1}{|c|}{ Municipio } & $\begin{array}{c}\text { Solicitudes de } \\
\text { restitución a } \\
2016^{17}\end{array}$ & $\begin{array}{c}\text { Total } \\
\text { sentencias } \\
\text { publicadas }^{8}\end{array}$ & $\begin{array}{c}\text { Sentencias } \\
\text { formalización } \\
\text { sin oposición }\end{array}$ & $\begin{array}{c}\text { Sentencias con } \\
\text { oposición entre } \\
\text { campesinos }\end{array}$ & $\begin{array}{c}\text { Sentencias } \\
\text { con opositor/ } \\
\text { concentrador } \\
\text { de tierra }\end{array}$ \\
\hline Chibolo & 417 & 2 & 35 & 69 & 2 \\
\hline $\begin{array}{l}\text { El Carmen de } \\
\text { Bolívar }\end{array}$ & 2191 & 127 & 5 & 18 & 0 \\
\hline Ovejas & 895 & 23 & 23 & 0 & 0 \\
\hline María la Baja & 367 & 23 & & & 23 \\
\hline San Onofre & & Sin sentencias & & & \\
\hline
\end{tabular}

Fuente: cálculos de los autores con base en información de la página web de la Unidad de Tierras.

\subsection{Limitaciones}

Teniendo esto en cuenta, se estimó un MSE tanto en escenarios de población abierta como cerrada. En el caso específico de las estimaciones para la población abierta, se supone que la probabilidad de captura de los individuos en cada una de las ocasiones de captura es igual. Este supuesto, aunque es restrictivo e irreal, es necesario, pues por problemas del paquete R-capture del software R (Baillargeon y Rivest, 2007), por el momento, fue imposible realizar los cálculos para poblaciones con diferentes probabilidades de captura.

A pesar de esto, se hicieron varias simulaciones en las que se cambió el orden de las bases con el fin de que se simularan diferentes probabilidades de captura, sin que esto comprometiera significativamente los resultados encontrados.

\section{Los problemas}

En la anterior sección hemos visto las diferencias que hay entre tres cifras: el despojo reportado - por ejemplo, a la Unidad de Tierras o al

17 Está información se encuentra en el siguiente enlace de la Unidad de Restitución: http:// cifras.unidadvictimas.gov.co/tierras

18 El número de sentencias corresponden a las publicadas en la página web de la Unidad de Restitución a marzo del año 2017. 
RUV-, la magnitud de la respuesta del Estado -operacionalizada en términos de sentencias- y el despojo estimado -como resultado de la aplicación del MSE a nuestros datos-. Esas diferencias son enormes. Más aún, el MSE sugiere que la probabilidad de que un dato sea reportado está entre el $4 \%$ y el $11 \%$, con las respectivas desviaciones. Esto es, el multiplicador de subestimación de las cuentas oficiales con respecto del despojo podría estar entre 4 y 25 . En los municipios considerados en este artículo, de cada 9 a 25 despojados, el gobierno estaría 'capturando' uno para sus políticas sociales. Esto sucede así precisamente en municipios con niveles muy altos de despojo y desplazamiento, algunos de los cuales han sido foco de atención tanto del Estado como de organizaciones no gubernamentales durante años.

La pregunta de por qué se produce una subestimación de semejante magnitud precisamente en esos municipios se sugiere a sí misma. La respuesta reside en por lo menos los siguientes cinco factores:

\subsection{Información y creencias}

El Estado colombiano registra víctimas básicamente por demanda. Es decir, aquellos que sufrieron alguna victimización por causa del conflicto armado se acercan a una ventanilla y plantean su caso. Esta es la regla, que se aplica tanto al Registro Único de Víctimas como a la manera en que opera la URT. Como hay alguna clase de reparación, así sea solamente moral o en el muy largo plazo, se supone que las víctimas tienen incentivos para hacerlo. Para morigerar los efectos indirectos negativos de tales incentivos -es decir, que se presenten no víctimas con el objetivo de disfrutar de los incentivos-, hay una serie de exámenes que los aspirantes deben pasar para ser creídos. Estos exámenes no son en lo más mínimo triviales, como lo atestiguan las más de 24712 solicitudes de restitución que ha rechazado la URT, por razones aún desconocidas (Verdad Abierta, 2017).

Aunque el Estado colombiano, y en particular el programa de restitución, desarrollaron una -no muy intensa- propaganda a favor de la política, omitieron tener en cuenta problemas informacionales muy serios que necesariamente debía tener una población, que en muchas ocasiones era ya vulnerable antes del despojo, y que después fue brutalmente golpeada. 
Tales problemas afectaron a la política de diversas maneras. Un porcentaje no insignificante de despojados nunca se enteró de su existencia. Como se ve en la figura 1, basada en una encuesta entre desplazados que perdieron sus tierras (Gutiérrez, García y Argoty, 2014), más de un $26 \%$ de ellos no se habían enterado de la existencia de un proceso de restitución. Otros lo conocían, pero en términos muy vagos; un porcentaje sustancial manifestaba no conocer sus derechos. Pero incluso entre los que sí sabían de su existencia había una profunda, y muy justificada, desconfianza con respecto del Estado. En poblaciones como las consideradas aquí, el Estado se había alineado con los paramilitares de manera sistemática. De hecho, incluso después de la desmovilización paramilitar, agencias y figuras como la policía y los alcaldes pudieron seguir apoyando a los despojadores, como fue el caso de Augusto Castro alias 'Tuto Castro' en el municipio de Chibolo, sobre el que hablaremos más adelante. Y aun si no existía la experiencia de haber sido víctima de la alianza entre despojadores y Estado, los reclamantes podían tener ya ideas muy formadas, y fundamentalmente negativas, acerca de la credibilidad de las promesas del Estado. Ni qué decir del difícil proceso para reclamar las tierras de aquellos que fueron víctimas de agentes estatales. Tan solo acercarse a la ventanilla pudo haber sido una experiencia bastante atemorizante.

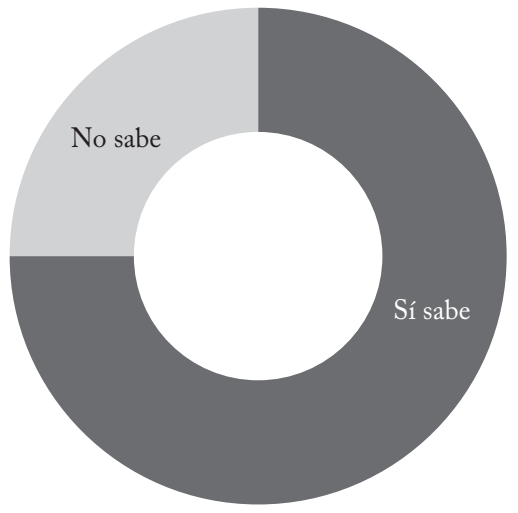

Figura 1. Respuesta a la pregunta: “Sabe si existe un programa de restitución?"

Fuente: reporte del Observatorio de Tierras y Derechos de Propiedad Agraria, La restitución y sus problemas. Recuperado de http://www.observatoriodetierras.org/wp-content/uploads/2014/01/REP.-2014-1-LARESTITUCI\%C3\%93N-Y-SUS-PROBLEMAS.pdf 
Hay que destacar que estos problemas informacionales no afectaron a toda la población de la misma manera. Aquellos con más recursos y con redes sociales o capital cultural pudieron estar más al tanto de sus derechos. Los más vulnerables se encontraron más aislados de la política. Por ejemplo, las mujeres (Gutiérrez et al., 2014) han sufrido claramente un déficit informacional a lo largo de la implementación de la política. Por lo tanto, los problemas no han afectado a la población de modo uniforme, sino diferenciada, golpeando a aquellos que están en peor situación.

Por consiguiente, ya desde el comienzo tenía que haber un número sustancial de víctimas que simplemente no se acercaron a la ventanilla a reclamar sus tierras.

\subsection{El diseño institucional -un diseño de fila-}

Como fue demostrado en el documento del Observatorio (2013), y como los acontecimientos ulteriores han venido a corroborar, el diseño institucional de la política de restitución básicamente corresponde a una fila, en donde los reclamantes se presentan y son atendidos caso por caso. La noticia positiva es que la eficiencia de la Unidad de Restitución para atender cada caso individual no ha sido mala. La noticia negativa es que es inevitable, incluso frente a este desempeño, que se forme 'un trancón fenomenal', habida cuenta del diseño de fila y de la magnitud del fenómeno del despojo y el abandono con pérdida de tierras. El fenómeno fue demasiado masivo para lo que permitía atender el diseño institucional, o al menos su arquitectura básica. Es cierto que había aspectos legales que permitían ir más allá de la atención predio por predio (por ejemplo, los casos de restitución de derechos territoriales de las comunidades indígenas y afrodescendientes), pero en los municipios estudiados en este trabajo no han sido tomados en consideración. ${ }^{19}$

19 Además, hay que precisar que, en cuanto la restitución de los derechos territoriales, estos procesos se han visto obstaculizados por la creación de un equipo en 2015 dentro de la Unidad de Restitución de Tierras denominado Equipo de Asuntos Ambientales, Minero-Energético y de Infraestructura (AMEI), el cual se ha convertido en un freno para la restitución, puesto que ha implicado que toda demanda de restitución deba ser revisada por este nuevo organismo, de tal manera que la solicitud no entre en contravía con los proyectos minero-energéticos e infraestructurales del gobierno en determinados territorios (Verdad Abierta, 24 de julio de 2016). 
Una cantidad grande de casos no atendidos puede generar varios fenómenos. Uno de ellos es simplemente el desistimiento, es decir, aquellos que observan la evolución de la fila y deciden no entrar a ella. A medida que pasa el tiempo, los desistimientos podrían hacerse mayores, pues la intención de retornar disminuye. Nótese que en particular en el proceso de restitución hay tres cuellos de botella. Primero, en el momento de decidirse a entrar a la fila. Segundo, en el momento de ser aceptado o no como posible reclamante por la URT; este paso es aún una caja negra. Y tercero, en el tránsito desde que la reclamación es aceptada y se produce la sentencia respectiva y se devuelve el predio. Individualmente los reclamantes encuentran que este último se produce a ritmos aceptables (Gutiérrez et al., 2014), pero la tabla 4 de este artículo sugiere que hay una diferencia muy grande entre el número de solicitudes que entran y el número de sentencias, que podría no estar totalmente explicada por las solicitudes rechazadas.

\subsection{Estructuras de poder y realineamiento parcial}

Muchas de las estructuras de poder asociadas al despojo en nuestros cinco municipios mantienen una parte significativa de su poder. Y algunas de ellas han lanzado una campaña activa de oposición al programa de restitución. Una ilustración del fenómeno es el municipio de Chibolo.

Los políticos locales que se vincularon al proyecto paramilitar de las AUC en Chibolo se vieron implicados de manera directa en procesos de despojo, bien sea como beneficiarios o facilitadores. Los actores más importantes y activos en el despojo del municipio fueron el jefe paramilitar Rodrigo Tovar alias 'Jorge 40' y el político y gran ganadero Augusto Castro Pacheco 'Tuto Castro' (Quinche, 2016, p. 97). Según el tipo de vínculo que los campesinos tuvieran con las tierras, los grupos paramilitares y sus aliados utilizaron las ventas forzadas o la firma de escrituras y demás documentos en blanco; o se valían de las actuaciones del Incora/Incoder para revocar las adjudicaciones de los predios o instaurar caducidades administrativas. A pesar de la desmovilización paramilitar en el año 2006, en la cual participó el Tuto Castro, sus acciones en la región continuaron intimidando y afectando el retorno de las víctimas del conflicto (Corte Suprema de Justicia, 2010). Entre los años 2006 y 2007, los campesinos 
desplazados del sector La Palizúa comenzaron un proceso de retorno a sus tierras sin acompañamiento estatal, y ocuparon las tierras, levantaron de nuevo sus ranchos y reiniciaron sus cultivos de pancoger -todo lo cual habían perdido con el abandono forzado de sus tierras diez años atrás-. En respuesta, Tuto Castro aprovechó su nueva condición de propietario 'legal' de los predios despojados 'La Boquilla', 'La Providencia' y 'Santa Martica', y su denotada influencia en el ámbito local para gestionar ante las autoridades locales (la Policía, la Alcaldía, la Personería del Pueblo) el desalojo de los campesinos retornados, tramitando querellas policivas de lanzamiento de ocupación de hecho, no una sino cuatro veces durante los años 2007 y 2008, las cuales siempre tuvieron respuesta positiva por parte de las autoridades (Castro, 2009).

Adicionalmente, en agosto del año 2009, Tuto Castro tramitó ante el Incoder una solicitud de revocatoria de adjudicación sobre los predios Villa Elisa y San Francisco, que les habían sido entregados en septiembre del año 2006 a Elisa Esther Púa Gámez y Luis Felipe Gámez Goelker (campesinos víctimas de la violencia en La Palizúa) por parte del Incoder en Resolución 1331, los dos ubicados en el predio 'Santa Martica' (Incoder, 2006). El Incoder responde positivamente e inicia a favor de Tuto Castro el trámite de revocatoria (Incoder, 2006). En noviembre de 2012, pese a que Tuto ya había sido capturado por la Policía Nacional - pues se le señalaba de hacer parte del 'ejército antirrestitución' que buscaba frenar el proceso de entrega de tierras a las familias que fueron despojadas en la región (El Heraldo, 11 de octubre de 2012) - y a que el Incoder ya había ordenado la extinción de dominio sobre los predios 'Santa Martica' y la 'Boquilla' (Verdad Abierta, 23 de febrero de 2017), la Alcaldía de Chibolo impartió una orden de desalojo mediante Auto 4 contra los campesinos, que exigían la reintegración de sus derechos sobre la propiedad de la tierra, sin una respuesta efectiva por parte del Estado (Informe Pueblo Nuevo, s. f.).

En municipios caracterizados por niveles hiperbólicos de desigualdad rural, institucionalidad precaria y una tradición larga de captura del Estado por parte de élites rurales y actores armados - muchas veces coludidos entre sí-, esos actores podrían tanto generar decisiones como tener poder de veto frente a otras durante períodos largos. Por eso, el realineamiento del Estado en el territorio - para pasar de ser un instrumento de los 
despojadores a un actor diferenciado y dotado de la proverbial "autonomía relativa" (Evans, 1996) - solo se ha producido de manera parcial. El fenómeno está bien capturado por la valoración misma de las víctimas, cuya evaluación del desempeño del Estado es bastante crítica (Gutiérrez et al., 2014). Al respecto, un activista local comentaba:

Aprendí mucho ahí, qué institucionalidad tenemos en Colombia, cómo manejan temas tan delicados. Ellos menosprecian los temas, y eso obliga a los campesinos a desconfiar, ya no hacen denuncias ni solicitudes, muchos. No hay garantía. Esto permite ver el tema de los ganaderos, cómo aprovechan el conflicto para apropiarse, cómo defienden lo de ellos, no mediante el derecho sino mediante el uso de la violencia. Y cómo la institucionalidad, de alguna manera, es cómplice, al no tener una posición dura sino flexible. Incluso, cómplice al atacar a las víctimas, desconociendo los derechos de los campesinos. Las instituciones creadas los están desconociendo, lo de la Unidad de Víctimas es viejo [...] En la Fiscalía... qué le dicen a la gente, "¿Usted cómo va a denunciar a ese señor? Ese señor no es capaz de hacer lo que usted está diciendo". ¿Cómo le vas a decir eso a una víctima? (activista local, Sincelejo, 15 de noviembre de 2016).

En efecto, un eslabón que sigue siendo críticamente débil en todo el proceso son las autoridades locales. Como se observa en la figura 2,

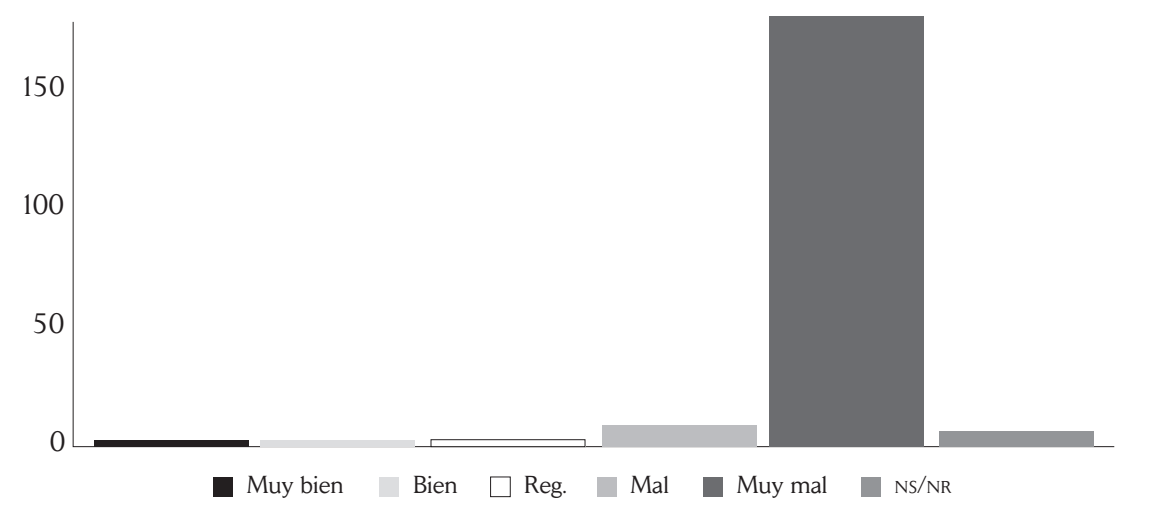

Figura 2. Evaluación de los alcaldes

Fuente: reporte del Observatorio de Tierras y Derechos de Propiedad Agraria, La restitución y sus problemas. Recuperado de http://www.observatoriodetierras.org/wp-content/uploads/2014/01/REP.-2014-1-LARESTITUCI\%C3\%93N-Y-SUS-PROBLEMAS.pdf 
la evaluación que se hizo de los alcaldes por parte de campesinos que habían perdido tierra en el sondeo del Observatorio (Gutiérrez et al., 2014) es bastante severa. Los desposeídos tienen la percepción de que los alcaldes no los representan y de que no atienden sus intereses. Parecería haber una fractura dramática entre el diseño que pretende incorporar las demandas de las víctimas a los procesos institucionales municipales y las preocupaciones de los alcaldes. Algo similar sucede con las personerías (Gutiérrez et al., 2014). Sobre esta problemática, se refiere una víctima en los siguientes términos:

Yo creo que nos resta unificarnos como sociedad civil en la región, pero solo como sociedad civil no podemos, debe haber una articulación con los entes locales y hacer cosas entre todos. Donde está el vacío es que a las autoridades territoriales no les interesan. Por ejemplo, anteayer teníamos programada una reunión en Colosó con todos los alcaldes de Montes de María y solo llegaron dos, San Juan y creo que el de Zambrano. Entonces, cuando uno se da cuenta de que a los entes territoriales no les interesa la información y la articulación de la sociedad civil, se da cuenta de que la sociedad es muy ardua. Todo se filtra es a través de los entes locales porque las organizaciones sociales no tenemos la estructura administrativa para administrar lo que desde lo nacional se quiere hacer en el territorio. Entonces, si a ellos no les interesa lo que estamos organizando, pues va a ser muy difícil (líder de víctimas, María la Baja, 9 de febrero de 2017).

En estas condiciones, las víctimas que perdieron tierras podrían tener razones elocuentes para buscar nuevos horizontes, o simplemente para abstenerse de entrar a la fila.

\subsection{Dificultades en la reconstrucción de los hechos}

Como se vio anteriormente, la ley incorpora -como debería hacerlo- varias formas de afectación de los derechos de propiedad que son objetivamente difíciles de probar, entre otras cosas porque el poder de los perpetradores y diversos diseños institucionales confluyen para producir múltiples 'territorios grises'. Dado que el diseño de la identificación 
de la víctima es por demanda, esto genera dos fuentes significativas de subestimación.

Por un lado, desde el punto de vista de las víctimas, la relación costo-beneficio de presentarse a hacer la fila puede ser al menos dudosa. El despojo en todo caso redefine la vida de sus víctimas. Significa una fractura severa en la trayectoria personal y familiar. Muchos de los despojados rehacen sus vidas en nuevos contextos ocupacionales y territoriales, y prefieren abandonar su predio para concentrarse en sus apuestas de futuro. A esto se suman factores etarios: 10, 15 o 20 años después de haber perdido su predio, los despojados son ya mucho mayores, tienen a sus hijos estudiando en el mundo urbano y se lo pensarán dos veces antes de involucrarse en un complejo proceso en el cual no saben si obtendrán la reparación ${ }^{20}$ (Gutiérrez et al., 2014).

Por otro, desde el punto de vista del Estado, las palabras que modifican la afectación de los derechos de propiedad ponen sobre el tapete problemas institucionales de larga data, cuya solución no se puede obtener en el actual contexto institucional. Por ejemplo, un aspecto clave de la Ley 1448 es que las ventas llevadas a cabo 'arbitrariamente' son sujeto de restitución. Esto tiene que ser así, porque una parte muy sustancial del despojo en los municipios considerados pasó por amenazas seguidas de la imposición de ventas a precios irrisorios. Pero el término arbitrariamente deja un complejo territorio gris por definir. Para poder dirimir muchos de los problemas inherentes a esta clase de calificación, se necesitaría tener claridad sobre los precios de mercado, por ejemplo. Por desgracia, dada la manera en que se avalúan los predios rurales en nuestro país -que permiten un amplio margen para una grosera subestimación-y las

20 Como se observa en las tablas 3 y 4 , la relación entre despojos/abandonos con pérdida de tierras y sentencias es bajísima; incluso lo es también la relación reclamaciones/sentencias. Esto puede deberse a diseños institucionales que están consignados en la Ley de Víctimas y que retrasan los procesos de restitución. Entre algunos de ellos puede mencionarse: 1) el requisito de la microfocalización, decisión que depende del Ministerio de Defensa; 2 ) el reducido número de jueces y magistrados para atender el cúmulo de solicitudes, que además se presentan de manera individual; 3) los tiempos estimados para resolver la solicitud (cuatro meses) no se cumplen, pues la información llega incompleta a los jueces de tierras; 4) antes de llegar la solicitud a los juzgados/tribunales, la Unidad de Tierras debe evaluar la inclusión o no del predio en el Registro de Tierras Despojadas y Abandonadas Forzosamente, y, una vez hecho el registro, armar la demanda para presentarla al juez competente, trámites que terminan prolongando aún más el proceso (ORDPA, 2016). 
tremendas debilidades de nuestro catastro, el Estado colombiano tiene apenas instrumentos muy imperfectos para captar realmente los precios de mercado y compararlos con las potenciales operaciones arbitrarias.

Algo análogo pasa con los comités municipales y departamentales de atención integral a la población desplazada -actualmente comités de justicia transicional-. Estos fueron creados para impedir ventas de bienes protegidos, pero, además de contar con dificultades para alinear a las autoridades locales, tienen fuertes problemas con respecto de la identificación de cuáles son los derechos de propiedad en juego. En muchos casos cruciales, carecen de los instrumentos para identificar y bloquear operaciones dudosas o ilegales. ${ }^{21}$

\section{Conclusiones}

Con base en un estimativo local, evaluamos la relación entre atendidos por la política de restitución y los potenciales beneficiarios de ella. Nos encontramos con que esa relación era muy mala, con diferencias entre uno y dos órdenes de magnitud. Es claro, por lo demás, que nuestro propio conteo debe de contener subestimaciones, ya que no incluimos muchas de las afectaciones a los derechos de propiedad que contempla la Ley

21 Un caso bastante representativo de esta situación se dio en el departamento de Bolívar en el marco de las compraventas masivas que se realizaron durante los años 2008-2010, principalmente en el municipio de El Carmen de Bolívar. Dada la magnitud de este fenómeno, por iniciativas de ciertos sectores de la sociedad civil se conformó un espacio alterno a los comités departamentales, denominado la Mesa de Sustanciación Departamental Integral de Atención a la Población Desplazada en el año 2009. La Mesa emitía un concepto al comité departamental, recomendando el levantamiento o no de la medida de protección según los siguientes criterios: el vendedor-solicitante de la autorización de enajenación no demostraba su titularidad sobre el predio; el vendedor de predio Incorado no cumplía con los requisitos para levantar medidas de protección en este tipo de predios; el comprador era propietario de algún predio Incorado o era poseedor de muchos predios alrededor del solicitado; la información suministrada a la Mesa de Sustanciación era contradictoria con información registrada en otras entidades u organismos. (Casos en los que se niega la propiedad de otros inmuebles ante la Mesa pero, según registros del IGAC, se evidencia lo contrario) (Documentos de la Mesa de Sustanciación de Bolívar, 2009). Pese a estos posibles controles que se hicieran para detener las compras de tierras en El Carmen, algunos levantamientos de las medidas de protección se hicieron a partir no de los comités departamentales, sino de las instancias municipales. Lo que han arrojado las sentencias de restitución es que el levantamiento de estas medidas de protección en el municipio señalado se hicieron de manera irregular sin tener en cuenta la situación de desplazamiento de las víctimas (Tribunal Superior del Distrito Judicial de Cartagena, Sala Civil Especializada en Restitución de Tierras. 132443121002201300062-00. 18 de febrero de 2016). 
1448. ${ }^{22}$ Ciertamente, nos hemos esforzado por excluir de nuestro cálculo actividades concentradoras de tierras que no involucren dimensiones ilegales y/o violentas (piénsese en los efectos de los llamados macroproyectos, sobre los que hay poca claridad), ${ }^{23}$ no porque las consideremos malas o buenas, sino simplemente porque es otra clase de fenómeno, que en principio debe ser tratado por separado.

A renglón seguido, hicimos una evaluación de las fuentes de subestimación que podrían explicar las diferenciales tan marcadas entre la población de potenciales beneficiarios y la de aquellos que finalmente han sido incorporados a la política. Encontramos que había al menos cinco: problemas informacionales, el diseño de fila (básicamente predio a predio) de la política, estructuras de poder y realineamiento apenas parcial del Estado, dificultades en la reconstrucción de los hechos y las realidades posdespojo (es decir, la acumulación ilegal de tierras creó hechos cumplidos que aprovecharon no solo los despojadores, sino otros agentes). Ellos interactúan entre sí.

En vista de la existencia de estos mecanismos, es esencial un rediseño y un relanzamiento del programa de restitución, coordinándolo con otros programas de acceso a tierras. No es que la restitución haya sido trivial o insignificante; mejoró la existencia de miles de campesinos, construyó un aparato administrativo pequeño pero serio y realineó parcialmente al Estado con respecto a los poderes en diversos territorios. Deja un importante patrimonio de experiencias positivas. Es inevitable, además, que esté sometida a debate (Fay y James, 2009).

Pero esa política apenas ha arañado la superficie. Hicimos la estimación que muestra esto en los casos más improbables (allí donde se concentra la atención del Estado, de ONG y de actores nacionales e internacionales), y presentamos los mecanismos que explican por qué es así. Hay que tener en cuenta que la restitución es una política concebida a término fijo. La figura 3 ilustra la evolución fiscal prevista para ella en el Conpes dedicado a ella. El panorama que dibuja esta evolución es

22 Y recuérdese que ella, de por sí, tiene límites, cuya magnitud está por evaluar.

23 Ver el reporte de Codhes (2013); Efectos concentradores de tierra producto de la siembra de palma africana en María la Baja (Bolívar) y Tibú (Norte de Santander) (González, 2015; Molano, 2012; Uribe Kaffure, 2014). 
bastante preocupante, por cuanto muestra que difícilmente se podría hacer más en términos de política de restitución de lo que se ha hecho con los recursos acopiados para ella. ${ }^{24}$

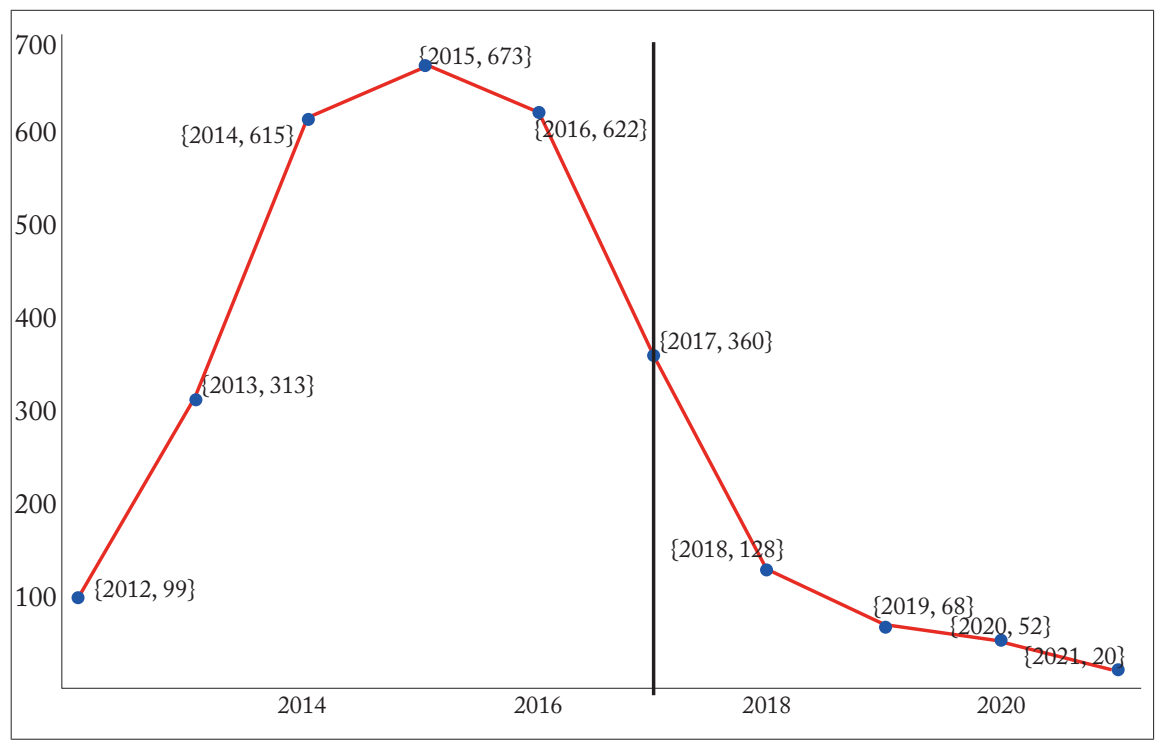

Figura 3. El ciclo de vida fiscal de la restitución

Fuente: elaboración de los autores con base en cifras de la Unidad de Restitución.

\section{Referencias}

\section{Literatura académica}

Ball, P. (2007). Los desaparecidos en el Casanare. Recuperado de https://hrdag. org/content/colombia/casanare-missing-report-final-ES.pdf

Ball, P. (2008). ¿Quién le hizo qué a quién? Planear e implementar un proyecto a gran escala de información en derechos humano. Benetech.

Baillargeon, S., \& Rivest, L. P. (2007). Recapture: loglinear models for capturerecapture. Journal of Statistical Software, 19(5), 1-31.

24 Es importante resaltar que en marzo de 2017 el gobierno asignó 12000 millones de pesos únicamente a la rama judicial para que agilizara los procesos en los juzgados y tribunales especializados (El Espectador, 4 de marzo de 2017). 
Céspedes Báez, L. M. (2010). La violencia sexual en contra de las mujeres como estrategia de despojo de tierras en el conflicto armado colombiano. Revista Estudios Socio-Jurídicos, 2, 273-304.

CNMH. (2016a). Tierras y conflictos rurales. Historia, políticas agrarias y protagonistas.

CNMH. (2016b). Anexo tierras y conflictos rurales. Recuperado de http://www.centrodememoriahistorica.gov.co/informes/informes-2016/tierras-y-conflictos-rurales

CNRR. (2009). El despojo de tierras y territorios. Aproximación conceptual.

CNRR. (2010). La tierra en disputa: memorias del despojo y resistencia campesina en la costa Caribe: 1960-2010. Bogotá: Comisión Nacional de Reparación y Reconciliación.

De los Ríos, E. (2011). La región de Montes de María: escenario actual de riesgo y de violación de derechos en Colombia. ILSA.

Evans, P. (1996). El Estado como problema y como solución. Desarrollo Económico, 35(140), 529-562.

Fay, D., E James, D. (2009). The rights and wrongs of land restitution. "Restoring what was ours". Nueva York: Routledge-Cavendish.

Franco, V., \& Restrepo, J. (2011). Empresarios palmeros, poderes de facto y despojo de tierras en el Bajo Atrato. En M. Romero (Ed.), La economía de los paramilitares. Redes de corrupción, negocios y política. Corporación Nuevo Arco Iris.

García Reyes, P., \& Vargas Reina, J. (2014). Transacciones sobre la tierra y conflicto violento, una lectura sobre los casos de Turbo, Antioquia y El Carmen de Bolívar, Bolívar. Análisis Político, 27(82), 22-44.

García, P., E Pardo, B. (2016). Censo de población beneficiaria del proceso de restitución en Montes de María. Bogotá: Observatorio de Restitución y Regulación de los Derechos de Propiedad Agraria.

Garay, L., Barberi, F., Perry, S., Ramírez, C., E Vargas, F. (2011). Cuantificación y valoración de las tierras y los bienes abandonados o despojados a la población desplazada. Comisión de Seguimiento a la política pública sobre desplazamiento forzado. Recuperado de http://www.coljuristas.org/documentos/adicionales/inf_tierras_2010-2011_01_06.pdf

González, C. (2013). La verdad en el abandono forzado y el despojo de las tierras. Presentado en el panel Diálogo de la Memoria: Territorio y Despojos, Bogotá, D.C.

González, N. E. (2015). Palma aceitera: conflictos y resistencias territoriales en María la Baja - Bolívar, Colombia. Eutopía - Revista de Desarrollo Económico Territorial, (8), 113-124.

Grajales, J. (2011). The rifle and the title: paramilitary violence, land grab and land control in Colombia. Journal of Peasant Studies, 38(4), 771-792. DOI: https://doi.org/10.1080/03066150.2011.607701 
Gutiérrez, F., García, P., E Argoty, C. (2014). La restitución y sus problemas según sus principales beneficiarios. Observatorio de Restitución y Regulación de Derechos de Propiedad Agraria. Recuperado de http://www.observatoriodetierras.org/ wp-content/uploads/2014/01/REP.-2014-1-LA-RESTITUCI\%C3\%93N-Y-SUSPROBLEMAS.pdf

Gutiérrez Sanín, F. (2014). Propiedad, seguridad y despojo: el caso paramilitar. Estudios Socio-Jurídicos, 16(1). Recuperado de http://revistas.urosario.edu.co/ index.php/sociojuridicos/article/view/esj 16.1.2014.01

Gutiérrez, F., E Vargas, J. (2016). El despojo y sus perpetradores. ¿Quién le quitó qué a quién y por qué? Universidad del Rosario.

Ibáñez, A., Moya, A., E Velásquez, A. (2006). Resumen ejecutivo. Hacia una política proactiva para la población desplazada. Recuperado de http://www.derechos. org/nizkor/colombia/doc/desplazada.html

Lefkaditis, P., E Ordóñez Gómez, F. (2014). El derecho a la reparación integral en justicia y paz: el caso Mampuján, Las Brisas y veredas de San Cayetano. Bogotá: ILSA. LeGrand, C. (2016). Colonización y protesta campesina en Colombia (1850-1950). Bogotá: Universidad Nacional, 1988. Republicado Bogotá: Ediciones Uniandes, con prólogo de Francisco Gutiérrez.

Mooney, D., E Swift, R. (1999). A course in mathematical modeling. Washington: Mathematical Association of America.

Observatorio de Restitución y Regulación de los Derechos de Propiedad Agraria. (2013). Un trancón fenomenal: un análisis de las demoras en el proceso de restitución. Bogotá.

Observatorio de Restitución y Regulación de los Derechos de Propiedad Agraria. (2016). Restitución de tierras cuatro años después. Recuperado de http://www. observatoriodetierras.org/wp-content/uploads/2014/01/Restituci\%C3\%B3nde-tierras-4-a\%C3\%B1 os-desp\%C3\%BAes.pdf

Quinche, J. (2016). El despojo de tierras paramilitar en Chivolo, Magdalena. En F. Gutiérrez \& J. Vargas (Eds.), El despojo paramilitar y su variación: quiénes, cómo, por qué. Bogotá: Universidad del Rosario.

Reyes, A. (2009). Guerreros y campesinos. El despojo de la tierra en Colombia. Norma. Rivest, L. P., E Daigle, G. (2004). Loglinear models for the robust design in mark-recapture experiments. Biometrics, 60(1), 100-107.

Salinas, Y., E Zarama, J. M. (2012). Justicia y paz. Tierra y territorios en las versiones de los paramilitares. Centro Nacional de Memoria Histórica: Bogotá. Recuperado de: http://centrodememoriahistorica.gov.co/descargas/informes2012/justicia_tierras.pdf 
Schwarz, C. J. (2001). The Jolly-Seber model: more than just abundance. Journal of Agricultural, Biological, and Environmental Statistics, 6(2), 195-205. Recuperado de http://www.jstor.org/stable/1400469

Schwarz, C. J., E Arnason, A. N. (2006). Jolly-Seber models in MARK. Program MARK "A Gentle introduction".

Seber, G. A. (1965). A note on the multiple recapture census. Biometrika, 52, 249-259.

Thomson, F. (2011). The agrarian question and violence in Colombia: conflict and development. Journal of Agrarian Change, 11(3), 321-356.

Uribe Kaffure, S. (2014). Transformaciones de tenencia y uso de la tierra en zonas del ámbito rural colombiano afectadas por el conflicto armado. Aproximación desde un estudio de caso. Estudios Socio-Jurídicos, 16(1), 243-283. Recuperado de https://doi.org/10.12804/esj16.1.2014.06

\section{Documentos gubernamentales y ONG}

Amnistía Internacional. (2014). Un título de propiedad no basta. Por una restitución sostenible de tierras en Colombia. Recuperado de file://C:/Users/Hogar/ Downloads/Informe\%202014\%20Aminist\%C3\%ADa\%20Internacional,\%20 Un\%20t\%C3\%ADtulo\%20de\%20propiedad\%20no\%20basta.pdf

ANUC, \& Corporación Nuevo Arco Iris. (2011). Diagnóstico básico integral de la situación social, política y económica del campesinado de la región de los Montes de María.

Codhes. (2013). Documento Codhes 26. La crisis humanitaria en Colombia persiste. El Pacífico en disputa.

Colombia, Ministerio de Agricultura y Desarrollo Rural. (2016). Restitución de tierras. Recuperado de https://www.minagricultura.gov.co/atencion-ciudadano/ preguntas-frecuentes/Paginas/Restitucion-de-Tierras.aspx

Comisión Intereclesial de Justicia y Paz. (2009). Gobierno financió cerca del 100\% de la palma. Recuperado de http://justiciaypazcolombia.com/GOBIERNOFINANCIO-CERCA-DEL-100-DE

Corporación Jurídica Yira Castro. (2011). La tierra botín de guerra. Recuperado de http://cjyiracastro.org.co/wp-content/uploads/2017/02/462_LA-TIERRABOTIN-DE-GUERRA.pdf

Forjando Futuros. (2014). Restitución de tierras gota a gota. Avances y dificultades. Recuperado de http://forjandofuturos.org/documentos/informe-generalrestitucion-de-tierras-2014-12.pdf 
ILSA. (2012). Montes de María: entre la consolidación del territorio y el acaparamiento de tierras. Bogotá, D.C.

Movice. (2010). Desplazamiento forzado y legalización del despojo en San Onofre: la comunidad que denunció la alianza parapolítica por la consolidación del control territorial. ILSA.

Oficina Internacional de Derechos Humanos (OIDH). (2013). Tierra en Colombia. Entre despojo y negocio. Presentación de la situación actual de una problemática al centro del conflicto.

PNUD. (2011). Desplazamiento forzado: tierras y territorios. Agendas pendientes, la estabilización socioeconómica y la reparación. Bogotá, D.C.

Programa Mundial de Alimentos. (2011). Estudio de caso de las necesidades alimentarias de la población desplazada de Colombia. Recuperado de http://reliefweb. $\mathrm{int} / \mathrm{report} /$ colombia/estudio-de-caso-de-las-necesidades-alimentarias-de-lapoblaci $\%$ C3\%B3n-desplazada-de

Proyecto Protección de Tierras y Patrimonio de la Población Desplazada. (2009). Conceptos relacionados con la ruta de protección étnica. Recuperado de http:// centromemoria.gov.co/wp-content/uploads/2013/10/Tierras_Ruta_Proteccion_Etnica.pdf

Superintendencia de Notariado y Registro. (2011a). Informe ejecutivo. Situación registral de predios rurales en los Montes de María. Bogotá: mimeo.

Superintendencia de Notariado y Registro. (2011b). Informe ejecutivo. Situación registral de predios rurales en los municipios de Apartadó, Arboletes, Necocli, San Juan de Urabá y Turbo. Región del Urabá Antioqueño.

URT Bolivar. (2014). Informe rendición de cuentas territorial Bolivar 2013. Recuperado de https://www.restituciondetierras.gov.co/documents/10184/680522/ Bolivar+Informe+Previo+2013.pdf/6f6789df-551f-4d13-b4997e5150b33589

URT Magdalena. (2014). Informe rendición de cuentas territorial Magdalena 2013. Recuperado de https://www.restituciondetierras.gov.co/documents/10184/680522/Magdalena+Informe+Previo+2013.pdf/fb016df42986-4fdf-8654-8be0a6ec481d

URT Sucre. (2014). Informe de rendición de cuentas 2013. Recuperado de https://www.restituciondetierras.gov.co/documents/10184/680522/ Sucre+Informe+Previo+2013.pdf/803a 5 507-a753-44d1-9059ad67504228ea 


\section{Prensa}

(11 de octubre de 2012). Así cayó alias el Tuto Castro. El Heraldo. Recuperado de https://www.elheraldo.co/judicial/asi-cayo-alias-tuto-castro-85134

(12 de febrero de 2016). El reto de la restitución. Semana. Recuperado de http://www.semana.com/nacion/articulo/restitucion-de-victimas-en-colombia/507746

(18 de agosto de 2010). Graves denuncias en debate sobre desplazamiento, tierras y víctimas. El Espectador. Recuperado de http://www.elespectador. com/jscroll_view_entity/node/219823/full/x219823-p219817

(23 de febrero de 2017). Las dos caras de la restitución en Chibolo. Verdad Abierta. Recuperado de http://www.verdadabierta.com/restitucion-de-bienes/6565las-dos-caras-de-la-restitucion-en-chibolo

(24 de julio de 2016). ¿Para dónde va la restitución de tierras a indígenas y afros? Verdad Abierta. Recuperado de http://www.verdadabierta.com/luchapor-la-tierra/6346-para-donde-va-la-restitucion-de-tierras-a-indigenas-y-afros

(29 de noviembre de 2012). La Europa y su misterioso comprador. Verdad Abierta. Recuperado de http://www.verdadabierta.com/predios-a-bajos-precios/241especiales/especial-ovejas/4350-la-europa-y-su-misterioso-comprador

(29 de septiembre de 2013). "Palmicultores se asociaron para delinquir": juez. Verdad Abierta. Recuperado de http://www.verdadabierta.com/lucha-por-latierra/4920-palmicultores-se-asociaron-para-delinquir-juez

(4 de marzo de 2017). Rama judicial recibió $\$ 12000$ millones para acelerar restitución de tierras. El Espectador. Recuperado de http://www.elespectador. com/noticias/judicial/rama-judicial-recibio-12000-millones-para-acelerarrestitucion-de-tierras-articulo-682987

(5 de marzo de 2017). Unidad de Tierras ha rechazado 24712 mil solicitudes de restitución. Verdad Abierta. Recuperado de http://www.verdadabierta. com/restitucion-de-bienes/6574-unidad-de-tierras-ha-rechazado-24-712-milsolicitudes-de-restitucion

(5 de mayo de 2016). Policía y Unidad de Restitución de Tierras fortalecen intervención en Santa Marta. Radio Rodadero. Recuperado de http://radiomagdalena 1420am.com/policia-y-unidad-de-restitucion-de-tierras-foartalecenintervencion-en-santa-marta/

(6 de septiembre de 2016). "Argos no conformó ni fue cómplice de grupos armados ilegales": Tribunal. Verdad Abierta. Recuperado de http://www. verdadabierta.com/restitucion-de-bienes/6392-argos-no-conformo-ni-fuecomplice-de-grupos-armados-ilegales-tribunal. 
(Abril de 2016). Trabajando por Montes de María. Semana. Recuperado de http:// www.semana.com/nacion/articulo/fundacion-semana-y-usaid-conocieronnecesidades-de-la-comundad-de-montes-de-maria/469459

(Agosto de 2013). La barbarie que rodeó la siembra de palma en Chocó. Verdad Abierta. Recuperado de http://www.verdadabierta.com/despojo-detierras/4715-la-barbarie-que-rodeo-la-siembra-de-palma-en-choco

(s. f.). El posconflicto en los Montes de María. Semana. Recuperado de http:// www.fundacionsemana.com/sala-de-prensa/articulo/el-posconflicto-montesmaria/4125

Amat, Y. (28 de abril de 2013). "Política de restitución de tierras es irreversible": Ricardo Sabogal. El Tiempo. Recuperado de http://www.eltiempo.com/archivo/documento/CMS-12766813

Molano, A. (3 de marzo de 2012). Paramilitarismo y palma en el Catatumbo. Semana. Recuperado de http://www.elespectador.com/noticias/judicial/ paramilitarismo-y-palma-el-catatumbo-articulo-330074

Pino, J. P. (26 de marzo de 2013). Chibolo, el caso de mostrar de la restitución de tierras. La Silla Vacía. Recuperado de http://lasillavacia.com/historia/ chibolo-el-caso-de-mostrar-de-la-restitucion-de-tierras-43011

Restrepo, J. (enero de 2012). Del Ministro de Agricultura sobre la restitución de tierras. El Espectador. Recuperado de http://www.elespectador.com/opinion/ del-ministro-de-agricultura-sobre-la-restitucion-de-tierras-columna-320914

Reyes, A. (31 de octubre de 2012). El problema de la tierra en Colombia. Recuperado de https://alejandroreyesposada.wordpress.com/2012/10/31/el-problemade-la-tierra-en-colombia/

\section{Documentos judiciales}

Archivos expedientes judiciales Juzgados de Ejecución de Penas de Santa Marta: - Castro, A. (julio de 2009). Carta a director del Incoder.

- Corte Suprema de Justicia. (2010). Sentencia Jorge Castro Pacheco.

- Incoder. (8 de septiembre de 2006). Trámite de revocatoria directa de Resolución 1331.

- Informe Pueblo Nuevo. (s. f.). Acción humana por la paz y los derechos humanos.

Colombia, Congreso de la República. Ley de Víctimas y Restitución de Tierras 1448 de 2011. Decreto 4829 de 2011.

Colombia, Corte Constitucional. Sentencia T-330 de 2016. 
Tribunal Superior del Distrito Judicial de Cartagena, Sala Civil Especializada en Restitución de Tierras. 132443121002201300062-00. 18 de febrero de 2016.

\section{Archivos}

(2009). Documentos de la Mesa de Sustanciación de Bolívar.

\section{Entrevistas}

Activista local, Sincelejo, 15 de noviembre de 2016.

Líder de víctimas, María la Baja, 9 de febrero de 2017. 